\title{
Radiation, inflammation and the immune response in cancer
}

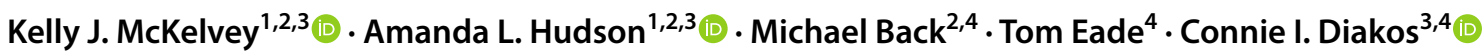

Received: 29 March 2018 / Accepted: 22 August 2018 / Published online: 3 September 2018

(c) The Author(s) 2018

\begin{abstract}
Radiation is an important component of cancer treatment with more than half of all patients receive radiotherapy during their cancer experience. While the impact of radiation on tumour morphology is routinely examined in the pre-clinical and clinical setting, the impact of radiation on the tumour microenvironment and more specifically the inflammatory/immune response is less well characterised. Inflammation is a key contributor to short- and long-term cancer eradication, with significant tumour and normal tissue consequences. Therefore, the role of radiation in modulating the inflammatory response is highly topical given the current wave of targeted and immuno-therapeutic treatments for cancer. This review provides a general overview of how radiation modulates the inflammatory and immune response-(i) how radiation induces the inflammatory/immune system, (ii) the cellular changes that take place, (iii) how radiation dose delivery affects the immune response, and (iv) a discussion on research directions to improve patient survival, reduce side effects, improve quality of life, and reduce financial costs in the immediate future. Harnessing the benefits of radiation on the immune response will enhance its maximal therapeutic benefit and reduce radiation-induced toxicity.
\end{abstract}

\section{Introduction}

The use of ionising radiation (IR) in the treatment of cancer has existed since the early 1900 s, since the realisation that the disposition of energy from photons, X-rays or gamma rays into cells and tissue leads to the death of cancer cells. Since then, radiation's inclusion in treatment paradigms has seen dramatic improvements in cancer survival. Radiation therapy (RT) outcomes in the last 20 years have improved dramatically with improved targeting by image guidance (Jaffray 2012), target volume delineation through positronemission-tomography and advanced magnetic resonance imaging (McKay et al. 2018) and more precise treatment

Kelly J. McKelvey

kelly.mckelvey@sydney.edu.au

1 Bill Walsh Translational Cancer Research Laboratory, Northern Sydney Local Health District Research and the Northern Clinical School, University of Sydney, St Leonards, NSW 2065, Australia

2 Sydney Neuro-Oncology Group, North Shore Private Hospital, St Leonards, NSW 2065, Australia

3 Sydney Vital Translational Research Centre, Royal North Shore Hospital, St Leonards, NSW 2065, Australia

4 Northern Sydney Cancer Centre, Royal North Shore Hospital, St Leonards, NSW 2065, Australia delivery to these targets through computerised 3D planning and beam modulation (Nutting et al. 2011). This has allowed radiation doses to be increased, tumour control improved, and side effects dramatically reduced. Despite improvements in outcomes for most cancers, biomarkers that assist in selecting patients in whom radiation will be successful, and is associated with quality of life and not treatment-limiting side effects, remains elusive. Changes here will be dependent upon understanding the cellular and molecular response of the tumour microenvironment to radiation.

The importance of the role of inflammation in patients with malignancy was epitomised by the inclusion of inflammation in the revised "Hallmarks of Cancer" (Hanahan and Weinberg 2011). In the clinical and research setting, a comprehensive understanding of IR and its ability to induce and modulate inflammation and the immune system remains largely in its infancy, but in order to improve patient survival, a better understanding is essential. In doing so, we may be able to better select patients who will benefit from RT, select the optimal RT dose and fractionation regimen, or be able to augment the response by altering the microenvironment with emerging targeted therapies and/or immunotherapies (Lan et al. 2018; Zhang and Niedermann 2018).

Here, we discuss how IR initiates and influences the inflammatory/immune system in the tumour microenvironment, and modulates immune cell populations. The critical 
role RT plays in the re-activation of the immune response for immediate and long-term cancer eradication will be discussed, with its role as a key adjuvant to upcoming targeted and immunotherapies, where a greater understanding is required if we are to improve global cancer survivorship.

\section{Radiation-induced immune mediators}

The current state of knowledge on the radiation-induced biological factors that can initiate a pro-inflammatory immune response within the tumour microenvironment are presented in (Fig. 1).

\section{DNA damage, reactive oxygen/nitrogen species, ER stress and hypoxia}

\section{DNA damage}

The old adage that radiation inflicts DNA damage primarily through direct interaction with macromolecules (nucleic acids, lipids, proteins) has long been dismissed. Only an estimated one-third of DNA damage is caused by the direct interaction of X-ray and $\gamma$-ray radiation hitting the macromolecule; the remaining two-thirds are due to indirect effects mediated by reactive oxygen/nitrogen species (ROS/ RNS) generation (Kang et al. 2012). DNA damage includes DNA strand breaks, DNA-DNA crosslinks, DNA-protein crosslinks and modification of the deoxyribose rings and bases. Estimates of the number of DNA double-strand breaks (DSB) in mammalian normal diploid cells per $1 \mathrm{~Gy}$ of IR range from 25 to 40 (Lobrich et al. 1994a, b; Olive 1999) to 1815 per cell (Buatti et al. 1992). This number varies greatly depending on the radiation type due to differences in the linear energy transfer (LET) of the irradiating photon/particle, a measure of the amount of energy the particle deposits as it traverses a unit of distance, and its subsequent relative biological effectiveness (RBE; Table 1). X-ray and $\gamma$-ray are sparsely ionising with low LET/RBE. They induce fewer single and DSB, and enable greater DNA repair whether it be homologous or non-homologous (Mitteer et al. 2015). In line with this, $X$-ray and $\gamma$-radiation requires high doses to elicit cell death. In contrast, particle and heavy ion radiation (emitting $\alpha$ and $\beta$ particles) are densely ionising with high LET/RBE inducing markedly more DSB for the same radiation dose (Table 1). Where the DSB exceed the cell's capacity for DNA repair cell death mechanisms are activated (see "Cell death and senescence").

As an example, irradiation of human peripheral blood lymphocytes induces threefold more cytotoxicity with proton radiation (dose rate [DR] $4.5 \mathrm{~Gy} / \mathrm{min}$ ), compared to X-ray irradiation (DR $9 \mathrm{~Gy} / \mathrm{min}$ ) across a dose range of 0.3-4 Gy (Miszczyk et al. 2018). Similar results were obtained with patient-derived glioma stem cells, where doses of 0-10 Gy proton irradiation (DR $2 \mathrm{~Gy} / \mathrm{min}$ ) induced more single and DSB, and $\sim 25 \%$ greater apoptosis when compared to X-ray radiation (DR $2 \mathrm{~Gy} / \mathrm{min}$ ). Akin to photon irradiation, induction of apoptosis by proton therapy is partially mediated by a
Fig. 1 Radiation-induced factors that initiate and modulate the inflammatory/immune response

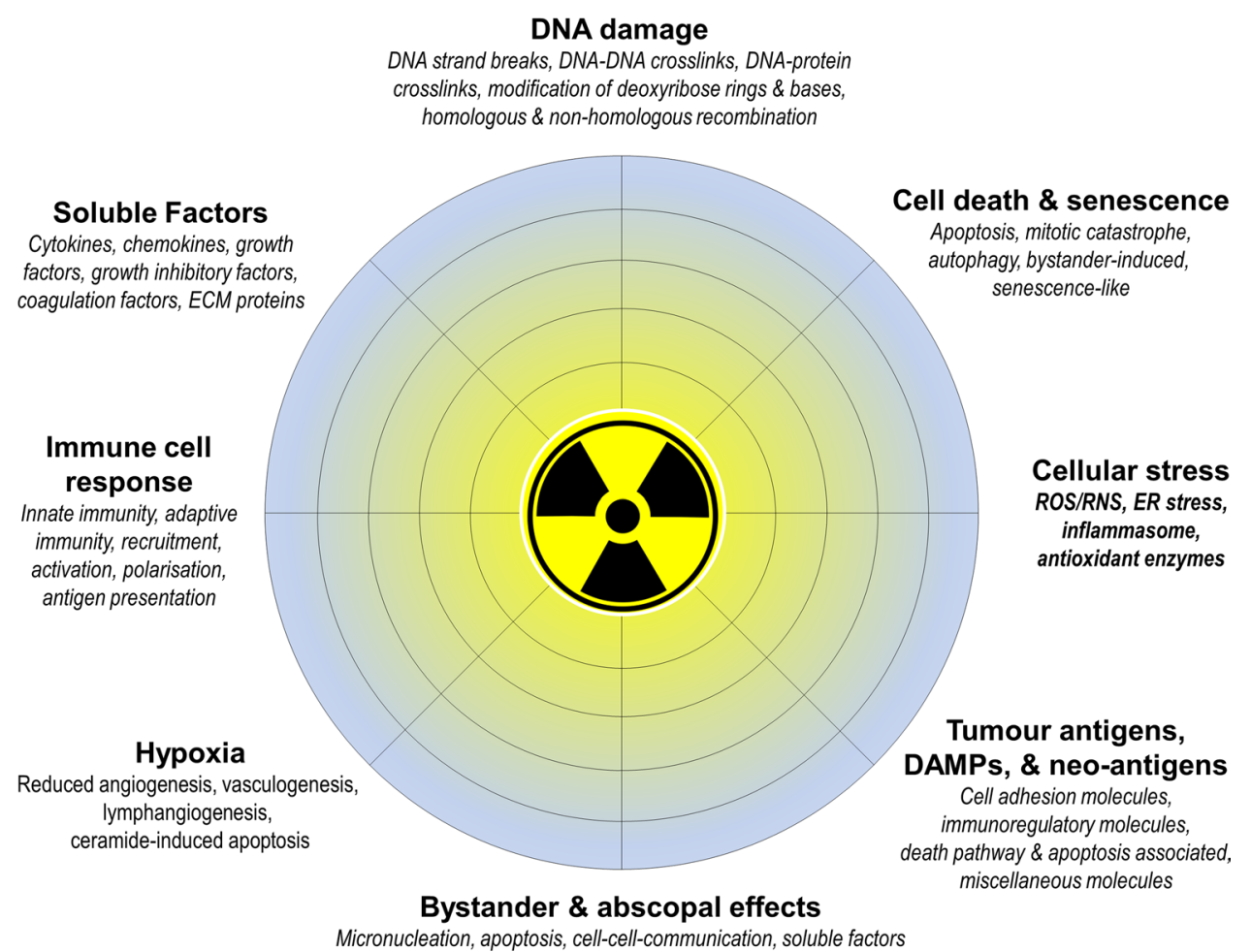

Micronucleation, apoptosis, cell-cell-communication, soluble factors 
Table 1 Historical and current IR types used for cancer RT

\begin{tabular}{|c|c|c|c|}
\hline & Source $^{\mathrm{a}}$ & Average energy & $\mathrm{RBE}$ \\
\hline \multicolumn{4}{|c|}{ External beam therapy } \\
\hline$\gamma$-ray & ${ }^{60} \mathrm{Co},{ }^{137} \mathrm{Cs},{ }^{192} \mathrm{Ir}$ & $0.4-1.3 \mathrm{MeV}$ & 1.0 \\
\hline X-ray & W & 4-18 MeV & 1.0 \\
\hline \multicolumn{4}{|c|}{ Particle and heavy ion therapy } \\
\hline Proton & $\mathrm{H}$-ion & $70-250 \mathrm{MeV}$ & $10-32$ \\
\hline Neutron & ${ }^{10} \mathrm{~B}$ & $50-70 \mathrm{MeV}$ & $10-32$ \\
\hline Heavy ion & C-ion & $450 \mathrm{MeV}$ & 20 \\
\hline \multicolumn{4}{|c|}{ Radionuclide therapy } \\
\hline$\alpha$-particle & $\begin{array}{c}{ }^{4} \mathrm{He},{ }^{213} \mathrm{Bi},{ }^{223} \mathrm{Ra}, \\
{ }^{225} \mathrm{Ac},{ }^{238} \mathrm{Pu}\end{array}$ & $5.5 \mathrm{MeV}$ & $10-20$ \\
\hline$\beta$-particle & ${ }^{106} \mathrm{Ru},{ }^{131} \mathrm{I},{ }^{177} \mathrm{Lu}$ & $10-200 \mathrm{keV}$ & $1.0-1.7$ \\
\hline
\end{tabular}

$A c$ actinium, $B$ boron, $B i$ bismuth, $C$ carbon, $C o$ cobalt, $C s$ caesium, $H$ helium, $I$ iodine, $I r$ iridium, $k e V$ kilovolt, $L u$ lutetium, $M V$ megavolt, $\mathrm{MeV}$ megaelectronvolt, $P u$ plutonium, $R a$ radium, $R u$ ruthenium, $R B E$ relative biological effectiveness, $W$ tungsten

${ }^{a}$ Superscript numbers denote the atomic mass (number of protons and neutrons) of the element

sevenfold up-regulation of ROS species 3 days after irradiation (Mitteer et al. 2015). These results are based on single dose fractionation (1fx). The RBE of radiation depends on the LET, cumulative dose, number and timings of fractions and the radiosensitivity of the targeted cells or tissues.

External beam RT, delivered in fractionated regimens, induces an accumulation of DNA strand breaks due to the failure to repair all breaks after each fraction, and is similar in acute- and late-responding tissues (Rube et al. 2010). Mice X-ray irradiated with $6 \mathrm{~Gy} / 3 \mathrm{fx}$ or $10 \mathrm{~Gy} / 5 \mathrm{fx}$ showed 3-4-fold more DSB compared to $2 \mathrm{~Gy} / 1 \mathrm{fx}$ (DR $2 \mathrm{~Gy} / \mathrm{min}$ ) (Rube et al. 2010). Human fibroblast cells irradiated with $6 \mathrm{~Gy} / 4 \mathrm{fx}$ show greater cytotoxicity than a single dose of 6 Gy (Rezacova et al. 2011). In contrast, irradiation of lymphocytic leukaemic cells with $4 \mathrm{~Gy} / 4 \mathrm{fx}$, compared to $4 \mathrm{~Gy} / 1 \mathrm{fx}$, showed similar survival. This may indicate that a minimum of 1.5 Gy per fraction is required to elicit a biological response, and those cells with a high proliferative index are less responsive to 'conventional' fractionated treatment due to an ability to undergo DNA repair. Hypo-, hyper-fractionation and 'ultra'-fractionation RT has shown some pre-clinical and clinical benefit over convention fractionation regimens in its modulation of the inflammatory response, in addition to alterations in DNA repair (Barlow et al. 2016; Stuschke and Thames 1997; Whelan et al. 2010).

\section{ROS/RNS}

IR passing through living tissues generates reactive oxygen/nitrogen species (ROS/RNS) and highly reactive hydroxyl $\left(\mathrm{OH}^{\circ}\right)$ and nitrosyl $(\mathrm{NO})$ radicals, superoxide $\left(\mathrm{O}_{2}{ }^{-}\right)$, peroxynitrite $\left(\mathrm{ONOO}^{-}\right)$, and hydrogen peroxide
$\left(\mathrm{H}_{2} \mathrm{O}_{2}\right)$. Each of these can damage cellular macromolecules including DNA, proteins or membranes via single and DSB, modification to deoxyribose rings and bases, intraand inter-strand DNA-DNA crosslinks, and DNA-protein crosslinks. These changes are deleterious if the cell is unable to repair the damage, or misrepairs the damage. The high cytotoxic efficacy of IR is attributed largely to ROS generated within $2 \mathrm{~nm}$ of DNA and the formation of complex DSBs. In glioma stem cells, a 50\% (X-ray) and $200 \%$ (proton) increase in ROS/RNS generation underpinned DNA damage and cell cycle changes leading to radiation-induced apoptosis (Mitteer et al. 2015). Proton and $\mathrm{X}$-ray irradiation-derived ROS induced single and $\mathrm{DSB}$, phosphorylation of histone $2 \mathrm{AX}$ and checkpoint kinase-2, reduced cell cycle recovery from $\mathrm{G} 2$ arrest, and activated caspase- 3 and poly(ADP-ribose) polymerase cleavage leading to cell death (Mitteer et al. 2015).

Radiation-induced ROS also modulate cellular changes through non-nuclear interactions summarised in (Fig. 2) by (i) damaging mitochondria, activating the nicotinamide adenine dinucleotide phosphate oxidase-1/Rac-1 pathway(Kang et al. 2012; Narayanan et al. 1997; Tateishi et al. 2008) or other oxidases; (ii) release of damageassociated molecular pattern proteins (DAMPs) and purinergic signalling molecules adenosine and adenosine triphosphate (ATP)-mediated by the purinergic receptor $2 \times 7$ (Ohshima et al. 2010); (iii) alterations in nuclear and cytosolic calcium flux $\left(\left[\mathrm{Ca}^{2+}\right]_{\mathrm{f}}\right)$ homeostasis responsible for cell cycle progression (Todd and Mikkelsen 1994); (iv) activation of ROS responsive protein kinases such as protein kinase $\mathrm{c}$ (PKC), mitogen-activated protein kinase (MAPK), apoptosis signal-regulating kinase-1, and the thioredoxin redox-sensing system (Fujino et al. 2006); (v) activation of 'cytokine-induced cell death' mediated by members of the TNF superfamily, including TNF- $\alpha / \beta$, Fas, TNF-related apoptosis-inducing ligand (TRAIL), TNFlike weak inducer of apoptosis (TWEAK), and TNFSF15 (Shakibaei et al. 2005); (vi) changes in expression of adhesion molecule, cytokine, chemokines, growth factor, proteases; (vii) activation of inflammasomes (see "Inflammasomes" section); and (viii) activation of the nuclear factor erythroid-2-related factor- 2 oxidative stress and antioxidant pathways (Bravard et al. 1999; McDonald et al. 2010; Tsukimoto et al. 2010).

The effects of ROS are amplified by the interaction of ROS/RNS with lipids, membranes and oxygen, and convergence with cytokine, DAMP and endoplasmic reticulum (ER) stress pathways (Fig. 2). In concert, these create a cyclic and self-amplifying cascade which contributes to a pro-inflammatory tumour microenvironment, bystander effects (see "Bystander and abscopal effect" section), and radiation-induced adverse events. 


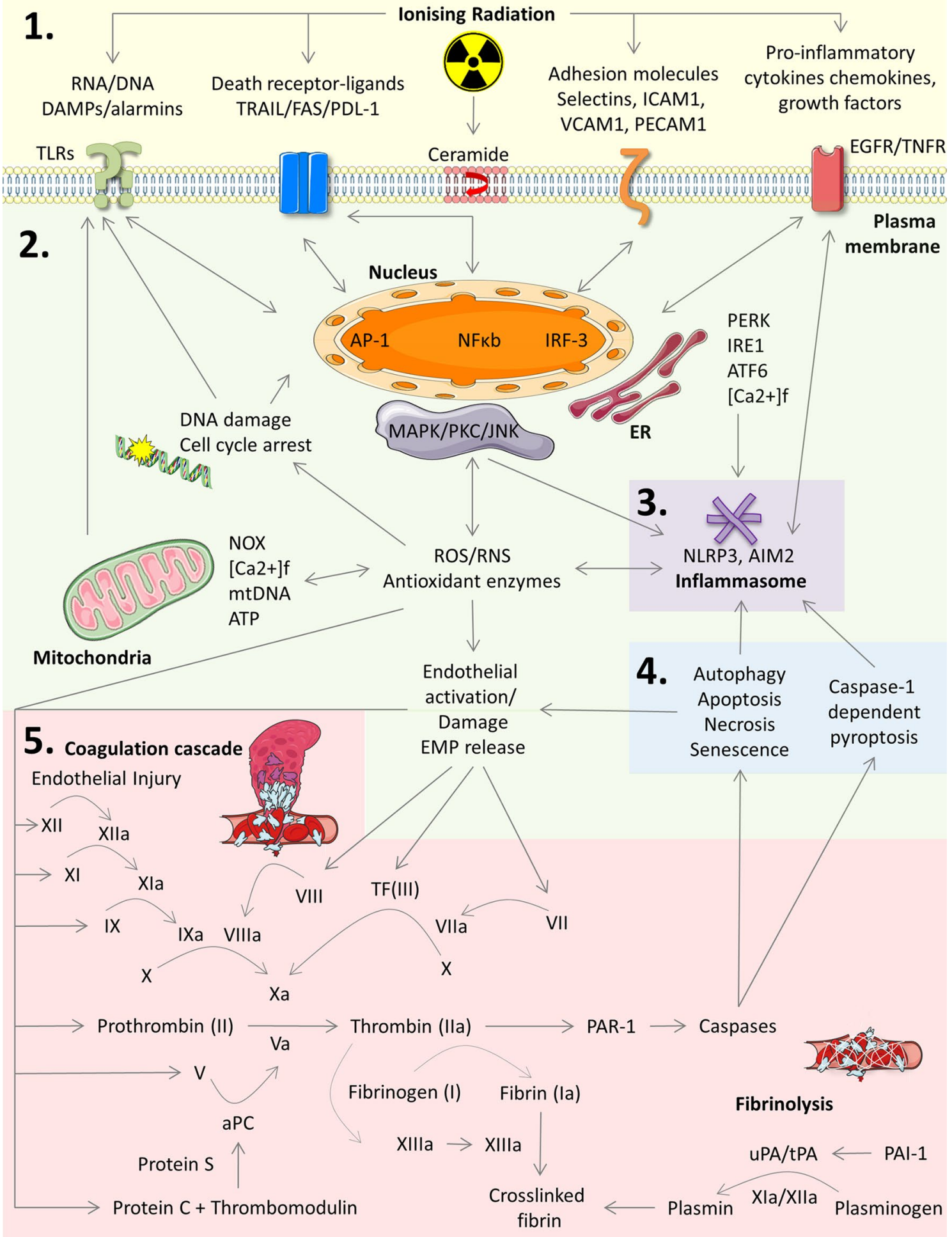

Fig. 2 Schematic overview of the interconnected network of inflammatory and immune response pathways activated by IR. Zones represent the topics discussed in this review; (1) cytokines, growth factors, adhesion molecules ("Cytokines, chemokines, growth factors, adhesion molecules and coagulation factors" section), (2) DNA damage, ER stress, ROS/RNS, hypoxia ("DNA damage, reactive oxygen/nitrogen species, ER stress, and hypoxia" section), (3) inflam- masomes ("Inflammasomes"), (4) cell death and senescence ("Cell death and senescence" section), and (5) coagulation and fibrinolysis ("Cytokines, chemokines, growth factors, adhesion molecules and coagulation factors" section). Straight arrows denote activation. Twoheaded arrows denote bidirectional activation. Curved arrows denote a catalytic or enzymatic action. Figure prepared using Servier Medical Art (https://smart.servier.com/) 


\section{ER stress}

Aside from nuclear interactions, IR can induce cytosolic effects altering the normal functioning of cellular ER, mitochondria and inflammasomes.

Dysfunction of ER protein folding activates protein kinase RNA-like ER kinase (PERK), activating transcription factor 6 (ATF6), and inositol-requiring enzyme 1 (IRE1) cell stress and unfolded protein response (UPR) pathways. These pathways aim to alleviate cellular injury but if exceeded trigger cell death mechanisms. 15 Gy ${ }^{137} \mathrm{Cs} \gamma$-irradiation of human umbilical vein and coronary artery endothelial cells (DR $3.51 \mathrm{~Gy} / \mathrm{min}$ ) activated the PERK/eukaryotic initiation factor $2 \alpha /$ ATF4 UPR signalling pathway (Kim et al. 2014). ${ }^{137} \mathrm{Cs} \gamma$-radiation (DR $0.79 \mathrm{~Gy} / \mathrm{min}$ ) of HL-7702 hepatoma cells activated the binding immunoglobulin protein (BiP)/ PERK/eukaryotic initiation factor $2 \alpha$ ER stress signalling pathway (Xie et al. 2016). X-ray radiation (DR $2.5 \mathrm{~Gy} /$ min) of human D54 and LN827 glioblastoma cells activated the ATF6/BiP/NOTCH1 ER stress pathway mediated by 45-78\% elevations in ROS levels (Dadey et al. 2016). 2 Gy carbon ion radiation of in vitro S180 cells and in vivo S180 sarcoma-tumour-bearing mice induced CHOP and BiP expression, and activation of the IRE1/c-Jun N-terminal kinase (JNK)/B-cell lymphoma (Bcl)-2/beclin-1/p62 ER stress pathway leading to autophagosome formation and apoptosis (Zheng et al. 2017). This effect was also achieved with 4 Gy X-ray irradiation. These data show that cell and/or radiation type may determine the ER stress pathway leading to the triggering of cell death mechanisms (see "Cell death and senescence" section). Interestingly, both the PERK/ eIF2a and IRE1/JNK ER stress pathways can trigger apoptosis and autophagy (Moretti et al. 2007).

In addition to ER stress and UPR pathways, irradiation of cells and tissues alters mitochondrial and inflammasome function. $4 \mathrm{~Gy}{ }^{137} \mathrm{Cs} \gamma$-radiation of rat brains induced DNA strand breaks, and mitochondrial cytochrome $\mathrm{c}$ and second mitochondria-derived activator of caspases release which activated caspases-3, -8 and -9 (Li et al. 2014). 3 Gy ${ }^{137} \mathrm{Cs}$ $\gamma$-irradiation (DR $0.83 \mathrm{~Gy} / \mathrm{min}$ ) of human HepG2 hepatocyte cells induced p53-dependent cytochrome c, NO and ROS release (He et al. 2011, 2012). The nucleotide-binding domain and leucine-rich repeat (NLRP3) and absent in melanoma (AIM)-2 inflammasomes form an integral part of the pathway from radiation-induced DAMPs and ROS/RNS to activated cytokines and are discussed in "Inflammasomes" section.

\section{Hypoxia}

Regions of hypoxic tissue are common in solid tumours and are thought to contribute to radiation resistance. Irradiation leads to a $20 \%$ loss of endothelial cells at 24 h (Pena et al.
2000 ) and a $46.5 \%$ reduction in tumour perfusion at 3-day post-radiation (El Kaffas et al. 2018). However, fractionated RT regimens can lead to re-perfusion, decreasing hypoxia within tumour supporting the 6 R's of fractionation; repair, repopulation, reoxygenation, redistribution, radiosensitivity and remote bystander effects. Endothelial cells contain very high level of ceramide synthase and acid-sphingomyelinase (Marathe et al. 1998), which following high-dose irradiation (8-10 Gy) lead to large amounts of acid-sphingomyelinaseinduced ceramide production and microvascular endothelial cell apoptosis (Paris et al. 2001; Pena et al. 2000). Lower doses of radiation, $0.5 \mathrm{~Gy}{ }^{137} \mathrm{Cs} \gamma$-radiation, also result in ceramide-induced apoptosis in bovine aortic endothelial cells (Haimovitz-Friedman et al. 1994). Loss of the blood microvasculature and oxygenation leads to the formation of hypoxic regions which can recruit immune cells and increase 'bystander' cytotoxicity. Murine prostate TRAMPC1 tumours irradiated with $25 \mathrm{~Gy} / 1 \mathrm{fx}$ or $60 \mathrm{~Gy} / 15 \mathrm{fx}$ showed a progressive decrease in microvascular density associated with decreases in CD31, endoglin, and tyrosine kinase with immunoglobulin-like and EGF-like domains 1 gene expression. Hypoxic regions surrounded centrally located dilated vessels and demonstrated infiltration and aggregation of $\mathrm{CD}^{+}{ }^{+}$tumour-associated $\mathrm{M} \phi$ (Chen et al. 2009). Tumour hypoxia enhances ROS-mediated cytotoxicity. ROS in conditioned media from irradiated HepG2 hepatocyte cells grown under hypoxic conditions showed enhanced micronuclei formation and apoptosis in non-irradiated HL-7702 hepatoma cells, compared to normoxic conditions (Xie et al. 2016).

Endothelial cells of the lymphatic vasculature are also injured by IR. 0,15 , or 30 Gy lead to the loss of lymphatic capillaries and a dose-dependent increase in lymphatic endothelial cell apoptosis (Avraham et al. 2010). Hypoxia increases CXCL12/CXCR4-mediated adherence of nonsmall cell lung carcinoma cells to lymphatic endothelial cells (Irigoyen et al. 2007), which may serve as a means of tumour metastases. While surgery is a primary contributor to the development of lymphedema in cancer patients, RT is also an independent risk factor with a tenfold increased risk in some patients (Hinrichs et al. 2004; Petrek et al. 2001). These data show that hypoxia can contribute to increased tumour cell death, but has also been implicated in tumour radio-resistance, tumour metastases and lymphedema as a long-term radiation-induced adverse event.

\section{Cell death and senescence}

The sensitivity of cells to radiation-induced cell death (loss of clonogenic capacity), as well as the type and timing/rate of cell death are determined by DNA damage repair/response system and the activation of specific groups of genes which control cell cycle checkpoints, inhibition of replication and 
transcription, induction of apoptosis, or an adaptive immune response (Szumiel 1998; Watters 1999). Probably, the most widely reported DNA damage sensors are tumour suppressor p53, poly(ADP-ribose) polymerase, DNA-dependent protein kinase, ataxia telangiectasia mutated protein, and to a lesser extent BRAC1/2, interferon regulatory factor-1, retinoblastoma, and cyclin kinase inhibitor $\mathrm{p} 21^{\mathrm{WAFI} / \mathrm{CIP} 1}$ (Szumiel 1998; Watters 1999). Irradiation of cancers induces a continuum of non-immunogenic/tolerogenic and immunogenic cell death mechanisms; autophagy, mitotic catastrophe, apoptosis, necrosis, 'cytokine or bystander-induced' and 'senescence-like' cell death which impacts the clinical outcome of RT (Lauber et al. 2012). However, there is still debate as to the immunogenicity of these different types of cell death (Gamrekelashvili et al. 2015). Irrespective of the mechanism of cell death, the generation of DNA damage, cell cycle arrest, cytokines, DAMPS, ROS/RNS, engagement of death receptors triggers, and activation of antigen presenting cells (see "Inflammatory and immune system cellular response" section) induces a cyclic pro-inflammatory tumour environment (Fig. 2).

It is interesting to note that the mechanism of cell death is influenced by radiation type as much as the above biological factors (Miszczyk et al. 2018). This is likely in part due to the difference in LET/RBE (Table 1) and therein the number of DNA strand breaks between the two radiation types. Wider studies and comparisons on how tumour and healthy cells die following irradiation of different radiation types, fractionation, and spatial modulation alone and in combination with various adjuvants-chemotherapy, targeted therapy, immunotherapy, oncolytic viruses, and vaccines are required.

\section{Autophagy}

Autophagy is a cytoprotective and cytocidal mechanism, whereby a cell digests a portion of cytoplasmic components to sustain cell metabolism and overcome radiation damage to macromolecules and organelles (Rubinsztein et al. 2007). Autophagy is regulated by a set of evolutionarily conserved genes which control autophagy induction, cargo packaging, vesicle nucleation, and expansion, retrieval, docking and fusion, and finally vesicle breakdown (Levine and Klionsky 2004). Inactivation of the autophagy and tumour suppressor gene beclin 1 induces spontaneous tumour formation in mice (Qu et al. 2003; Yue et al. 2003) and is monoallelically deleted in $40-75 \%$ of breast, ovarian and prostate cancers (Aita et al. 1999).

Radiation induces ROS-dependent and -independent DNA, lipid and protein damage in cells, as well as activating the ER stress pathway; both are capable of inducing autophagy (Chaurasia et al. 2016). $2-20$ Gy ${ }^{137} \mathrm{Cs}$ $\gamma$-radiation (DR $3.8 \mathrm{~Gy} / \mathrm{min}$ ) of malignant human glioma cell lines showed temporal and dose-dependent response patterns of autophagy and apoptosis from day 1 to 5 postirradiation (Jo et al. 2015). Radiation induced autophagy at days 1-7 post-irradiation for 5-20 Gy, and apoptosis from day 3 in lethal doses (10 and $20 \mathrm{~Gy}$ ) and day 7 in sub-lethal doses ( 2 and 5 Gy). These data show that there are temporal changes in the cell death mechanism with an attempt at non-immunogenic cell survival/cytoprotection (autophagy) made prior to the initiation of apoptosis, particularly with fractionated doses $(<5 \mathrm{~Gy})$. This may limit the initial inflammatory/immune response due to the relative absence of immunogenic tumour antigen, and supports tumour progression and recurrence.

\section{Mitotic catastrophe}

Mitotic catastrophe is delayed or aberrant mitosis followed by apoptosis, necrosis or complete fragmentation of interphase nuclei with eventual cell death. Morphologically, mitotic catastrophe is associated with the formation of multinucleate giant cells with uncondensed chromosomes. Irradiation leads to a range of disruptions to the cell cycle. For $\sim 6 \mathrm{~h}$ following $0.5-4$ Gy $\mathrm{X}$-ray irradiation, the activated $\mathrm{G}_{1}-\mathrm{S}$ checkpoint fails to efficiently prevent $\mathrm{S}$-phase entry by cells with unrepaired DSBs and other DNA damage. At $>6 \mathrm{~h}$, the checkpoint is inefficiently maintained leading to the formation of chromosome breaks at doses of 1-4 Gy during the $\mathrm{G}_{2}-\mathrm{M}$ phase(Deckbar et al. 2010). Similar effects to the $\mathrm{p} 53$-dependent $\mathrm{G}_{1}-\mathrm{S}$ checkpoint can be found with 5 Gy $\gamma$-radiation using mouse embryonic fibroblast cultures (Cann and Hicks 2006). When these cells enter M-phase, aberrant mitosis directly induces cell death via caspase- 2 activation, and/or indirectly through the release of mitochondrial cytochrome $\mathrm{c}$ and apoptosisinducing factor, and subsequent activation of caspase- 9 and -3 .

Cells show a significant difference in the susceptibility of DNA strand breaks to radiation, and in the ability to repair these breaks during different phases of the cell cycle. This concept underpins the use of fractionated RT in clinical practice. Using $3.5 \mathrm{~Gy}{ }^{137} \mathrm{Cs} \gamma$-radiation, McArt and colleagues show that cervical cancer cells (HeLa) were most susceptible to DNA damage during S-phase, and least during M-phase. Conversely, repair was most efficient during G1-phase and least during M phase (McArt et al. 2010). The level of DSB induced by $\mathrm{X}$-ray radiation during $\mathrm{G}_{1}$ or $\mathrm{M}$ phase does not correlate with cell killing (Iliakis and Okayasu 1988) with some cells of incomplete mitosis undergoing post-mitotic apoptosis; single fraction $\gamma$-radiation induced apoptosis in non-clonogenic cells three cell cycles after irradiation of normal human fibroblast and epithelial cells (Linke et al. 1997). 


\section{Apoptosis}

This traditional 'programmed cell death' is induced by radiation via intrinsic mechanisms-DNA damage sensors, cytokines, stress response, DAMPs, ceramide and ROS/RNS initiated signalling pathways discussed elsewhere, or extrinsic mechanisms - up-regulation of death receptors (Krysko et al. 2012). Radiation-induced apoptosis can be mediated by the up-regulation and engagement of death receptors Fas ligand (FasL), TRAIL, and programmed death-ligand-1 (PDL1) or their corresponding receptors. 2.5-10 Gy $\gamma$-radiation induced dose-dependent apoptosis, increased expression of TRAIL, TRAIL-R2, Fas, p53, and down-regulation of anti-apoptotic protein Survivin in neuroblastoma stem cells $6 \mathrm{~h}$ after RT (Ivanov and Hei 2014b). Radiation doses of 8-20 Gy up-regulate Fas on tumour cells (Chakraborty et al. 2003; Garnett et al. 2004) to mediate $\mathrm{CD} 8^{+}$cytotoxic T-cell (CTL) killing. 2-5 Gy $\gamma$-radiation induced low levels of apoptosis and induced a strong 'bystander effect' in nonirradiated cancer cells (Ivanov and Hei 2014b).

Investigation of 10 and $20 \mathrm{~Gy} / 1 \mathrm{fx}$ irradiation dosedependently up-regulated surface expression of Fas on 10 out of 23 different human carcinoma cell lines (6/12 colon, 2/7 lung, and 2/4 prostate) after $72 \mathrm{~h}$ (Garnett et al. 2004). In another study, repeat biopsies of lymphoma and squamous cell carcinomas after 4, 10, and 20 Gy cumulative dose RT showed absent to very low expression of Fas on the 52 squamous cell carcinomas, whereas $2 / 4$ malignant lymphoma showed high Fas expression after 4 and 10 Gy RT (Ogawa et al. 1997). $\gamma$-irradiation induced up-regulation of Fas and induction of $\mathrm{G}_{1}$ cell cycle arrest is dependent on p53 activity (Sheard et al. 1997). Combined, these studies indicate that radiosensitivity of cancers is type specific and may relate to Fas expression, whereby Fas/FasL expression can be upregulated in some cancers by high-dose single fraction or low-dose fractionated RT (Ogawa et al. 1997; Sheard et al. 1997). Identification of cancers types/subtypes or patients that do not up-regulate TRAIL/Fas expression following RT may help direct radiation treatment selection.

\section{Necrosis}

Of all the cell death mechanisms, necrosis is the most morphologically distinct, with profound cellular damage including clumping and degradation of DNA, swelling and rupture of the plasma membrane, organelle degradation, mitochondrial swelling, increased vacuolation and the release of DAMPs (Gamrekelashvili et al. 2015). Necrotic cell death was observed at doses of 0.3-4 Gy from both proton and $\mathrm{X}$-ray radiation (Miszczyk et al. 2018). The radiation type influenced the ratio of apoptotic:necrotic cell death with 25:75\% observed for proton therapy, and 40:60\% observed for X-ray therapy at 4-h post-irradiation. This suggests a greater tendency for necrosis with proton therapy. 5 Gy irradiation of human MG-63 osteosarcoma spheroids died by apoptosis through triggering $\mathrm{Bcl}-2$, Bax and $\mathrm{Bcl}-\mathrm{xL}$ in the apoptotic signalling pathway, while higher doses of $30 \mathrm{~Gy}$ induced necrotic cell death (Rainaldi et al. 2003). Combining these data shows that radiation dose and type influence the mechanism of cell death in tumour cells, likely attributable to the number of DSBs. This has implications for the selection of patients for appropriate RT regimens. For example, as well as the reduced entry/exit dose of radiation, 'cold/low-immunogenic' tumours such as glioblastoma may benefit more from proton therapy than conventional external beam RT, as apoptosis is considered less immunogenic than necrosis.

\section{'Cytokine'-induced, 'Bystander'-induced, and 'Senescence-like' cell death}

Cytokine engagement of receptors on neighbouring cells can trigger a cytokine cascade that upregulates death receptors on the cell surface, and/or induces cell death; IL-1 $\alpha$, IL-6, IL-8, TGF- $\beta 1$, TNF- $\alpha / \beta$ (Burdak-Rothkamm et al. 2007; Dong et al. 2015; Ivanov and Hei 2014a; Narayanan et al. 1999; Shao et al. 2007, 2008; Shareef et al. 2007). The interconnected network of pro-inflammatory cytokines, ROS and apoptotic ligands contributes to 'cytokine'- and 'bystander'-induced cell death. Bystander-induced cell death includes a wider range of initiating molecules secreted by irradiated neighbouring cells. These include the cytokines listed above and ROS/RNS responses NO, $\mathrm{O}_{2}^{--}, \mathrm{H}_{2} \mathrm{O}_{2}$ (Burdak-Rothkamm et al. 2007; He et al. 2012; Narayanan et al. 1997; Shao et al. 2007, 2008, 2003); ER stress response cytochrome c (He et al. 2011, 2012); and apoptotic pathways TRAIL, Fas, PDL-1, TWEAK and TNFSF15 (Ivanov and Hei 2014a, b; Lupu-Plesu et al. 2017; Shakibaei et al. 2005; Shareef et al. 2007).

As an alternative to cell death, cells with irreparable DNA damage are programmed to undergo premature senescence to maintain the integrity of the genome (so called senescentlike cell death) (Campisi and d'Adda di Fagagna 2007). Cells experience irreversible growth arrest, but the metabolic processes remain active. Such a response may prevent an immunogenic response to this 'self-sterilising' cell death. Senescent-like cell death is more common among cells of epithelial origin (Suzuki et al. 2001), compared to haematopoietic cells which predominantly undergo apoptosis due to the relative radiosensitivity of the cell types (Ross 1999). IR of normal human keratinocytes induced ROS-mediated premature senescence by the up-regulation of oxidase genes Lpo, p22-phox, p47-phox and Gp91 (Dong et al. 2015). Normal human diploid cells irradiated with X-ray radiation lead to permanent cell growth arrest through the accumulation of $\mathrm{p} 53$ and induction of $\mathrm{p} 21^{\mathrm{WAFI} / \mathrm{CIP} 1}$ and $\mathrm{p} 16$. 
The senescent-like state was associated with expression of senescence-associated beta-galactosidase, but not telomere shortening (Suzuki et al. 2001). Four Gy radiation induced apoptosis in $65 \%$ of murine bone marrow cells (Meng et al. 2003). After 5 weeks, 33\% of murine bone marrow cells survived irradiation but demonstrated a senescent phenotype; expression of senescence-associated beta-galactosidase, p53 and p2 $1^{\text {WAFI/CIP1 }}$, p16, and p19 and an inability to form colony forming units of granulocyte $M \Phi$ (Meng et al. 2003). Endothelial cells can undergo senescence when exposed to IR. Irradiated endothelial cells decrease NO production and expression of thrombomodulin (TM), and elevate levels of ROS, inflammatory cytokines and adhesion molecules. Functionally, the cells show an inability to proliferate and form vascular structures (Wang et al. 2016).

\section{Cytokines, chemokines, growth factors, adhesion molecules and coagulation factors}

Radiation activates the interconnected network of cytokines, adhesion molecule, ROS/RNS and DAMPs leading to a selfamplified cascade (Fig. 2), which generates pro-inflammatory, pro-oxidant tumour microenvironment and ultimately tumour cell death. Regulation of these molecules is controlled by transcription factors, tyrosine kinases and tumour suppressors. Table 2 summarises the inflammatory mediators within the tumour microenvironment that are modulated by IR.

Radiation dose, DR and fractionation modulates the aforementioned molecules. Pro-inflammatory cytokine induction requires 7-10 Gy (Hong et al. 1995), as does NF- $\mathrm{B}$ (Rho et al. 2005), while up-regulation of ICAM-1 was observed with doses as low as 2 Gy (Hong et al. 1995). Fractionation of radiation regimens can influence the persistence of pro-inflammatory cytokines in the tumour microenvironment. Irradiation of $\mathrm{C} 3 \mathrm{H} / \mathrm{HeJ}$ and $\mathrm{C} 57 \mathrm{BL} / 6 \mathrm{~J}$ murine lung with single (20 Gy) and fractionated doses (4 Gy/day) of radiation increased IL- $1 \beta$ within $1 \mathrm{~h}$ (single dose) and within $6 \mathrm{~h}$ (after each fractionated dose) (Hong et al. 1999). Fractionated radiation maintained a sustained up-regulation of cytokine gene expression for a longer period (Hong et al. 1999). The essential roles of ICAM-1, IL- $1 \beta$, and NF- $\kappa$ B in the induction of the radiation-induced immune response are depicted in Fig. 2.

Radiation-induced coagulopathy including haemorrhage and microvascular thrombosis are reported in preclinical animal models, cancer patients, and Hiroshima and Nagasaki atomic bomb victims (Gutin et al. 2009; Krigsfeld and Kennedy 2013; Lai et al. 2008; Robins et al. 2006; Stupp et al. 2005). Exposure to $1.8-80 \mathrm{~Gy}{ }^{137} \mathrm{Cs} \gamma$-radiation caused oxidation of Met388 at the thrombin-binding site of TM, leading to radiation dose-dependent impairment of the TMthrombin complex formation, and insufficient activation of protein C (Ross et al. 2008). Irradiation leads to changes in levels of coagulation factors (TM, factors II, V, VII, VIII, IX, X, XI and XII) and soluble fibrin, increasing blood clotting times, haemorrhage, and microvascular fibrin clots in lung, liver and kidneys of irradiated animals (Krigsfeld and Kennedy 2013; Krigsfeld et al. 2012, 2013). Disruption of the coagulation and fibrinolytic pathways is differentially affected by radiation DR. High DR $(0.5 \mathrm{~Gy} / \mathrm{min})$ increased prothrombin time (PT) due to Factor VII. In contrast, low DR (0.0083 Gy/min) increased PT values due to Factors II (prothrombin), V, and VII, and increased activated partial thromboplastin time (aPTT) mediated by Factor IX (Krigsfeld et al. 2012). As a part of the innate immune response, radiation-induced coagulation drives the immune response through the activation of caspases. Caspases cleave procytokines and pro-apoptotic molecules (e.g. pro-IL-1 $\beta$ and Bid) activating cell death pathways and eliciting a wideranging immune response (Fig. 2).

\section{Release of tumour antigen, DAMPs and neo-antigen generation}

Irradiation promotes the release of endogenous ligands, called DAMPs. These 'danger' signals represent a wide range of molecules including adenosine, ATP, DNA, mitochondrial DNA, receptor for advanced glycation end product ligands (e.g. heat shock proteins, S100 proteins, defensins, high-mobility group box-1 [HMGB1]), hyaluronan, oxidised phospholipids and oxidised cholesteryl esters, extracellular matrix proteins (e.g. fibronectin, hyaluronan, uric acid, and surfactant proteins) and polymorphonuclear neutrophil (PMN)-derived alarmins (Rosin and Okusa 2011; Schaue et al. 2012a). During inflammation, release of DAMPs into the extracellular space can occur via (i) expression on apoptotic cells or leakage from necrotic cells, (ii) increased synthesis and post-translational modification, and (iii) degradation of inactive precursors into toll-like receptor-mimetic degradation products (Mencin et al. 2009). Upon engagement with their receptor, DAMPs initiate self-amplified cytokine cascades leading to the activation of immunogenic cell death mechanisms (Sridharan and Schoenfeld 2015), innate immune responses (Miller et al. 2011), and inflammatory tissue (Schaue and McBride 2010).

Radiation can alter the immunogenicity of tumours and increase their susceptibility to immune recognition and clearance. Upon irradiation, tumour cells and tumourassociated endothelial cells express a wide range of 'novel' antigens (called 'neoantigens') including immune regulatory molecules - major histocompatibility complex (MHC) class I, CD80, CD20, CD94; death receptors and apoptosisassociated molecules_-Fas, FasL, TRAIL, phosphatidylserine; cell adhesion molecules-integrins $\left(\alpha_{2 b} \beta_{3}, \alpha_{5} \beta_{1}\right)$, cadherins (E-cadherin and $\alpha$-catenin), P-selectin, E-selectin, 
Table 2 Tumour microenvironment inflammatory mediators modulated by IR

\begin{tabular}{|c|c|c|c|c|}
\hline Mediators & Source & Dose/fraction & Tissue niche & References \\
\hline \multicolumn{5}{|l|}{ Transcription factors } \\
\hline NF-кB & $\alpha$-particle $\left({ }^{241} \mathrm{Am}\right)$ & $1 \mathrm{~Gy} / 1 \mathrm{fx}$ & $\begin{array}{l}\text { Human bronchial epithelial } \\
\text { cells (Beas-2B) condi- } \\
\text { tioned media on mac- } \\
\text { rophage cells (U937) }\end{array}$ & Fu et al. (2016) \\
\hline NF-кB, AP-1, Sp-1, p53 & $\gamma$-ray $\left({ }^{137} \mathrm{Cs}\right)$ & 5-30 Gy/1fx & Rat cerebral cortex & Raju et al. (2000) \\
\hline NF-кB, AP-1, CREB & $\gamma$-ray $\left({ }^{137} \mathrm{Cs}\right)$ & $10 \mathrm{~Gy} / 1 \mathrm{fx}$ & Rat brain & Lee et al. (2010) \\
\hline STAT-3 & $\gamma$-ray $\left({ }^{60} \mathrm{Co}\right)$ & $2-10 \mathrm{~Gy} / 1 \mathrm{fx}$ & $\begin{array}{l}\text { Human alveolar carcinoma } \\
\text { cells (A549) }\end{array}$ & Gao et al. (2014) \\
\hline $\mathrm{NF}-\kappa \mathrm{B}$ & $\alpha$-particle $\left({ }^{3} \mathrm{He}\right)$ microbeam & $0.5 \mathrm{~Gy} / 1 \mathrm{fx}$ & $\begin{array}{l}\text { Human skin and lung } \\
\text { fibroblasts }\end{array}$ & Zhou et al. (2008) \\
\hline $\mathrm{NF}-\kappa \mathrm{B}$ & $\mathrm{X}$-ray & $2-8 \mathrm{~Gy} / 1 \mathrm{fx}$ & $\begin{array}{l}\text { Murine microglia cells } \\
(\mathrm{BV}-2)\end{array}$ & Hwang et al. (2006) \\
\hline \multicolumn{5}{|l|}{ Tyrosine/protein kinases } \\
\hline PKC $\beta I I$ & $\gamma$-ray $\left({ }^{137} \mathrm{Cs}\right)$ & $1 \mathrm{~Gy} / 1 \mathrm{fx}$ or $10 \mathrm{~Gy} / 1 \mathrm{fx}$ & $\begin{array}{l}\text { Human lung fibroblast } \\
\text { (MRC-5) }\end{array}$ & Baskar et al. (2008) \\
\hline $\begin{array}{l}\text { Raf-1, MAPK, PKC } \gamma, \\
\text { PLC, } \mathrm{IP}_{3}\end{array}$ & $\gamma$-ray $\left({ }^{60} \mathrm{Co}\right)$ & $2 \mathrm{~Gy} / 1 \mathrm{fx}$ & $\begin{array}{l}\text { Human squamous carci- } \\
\text { noma cells (A431) }\end{array}$ & Dent et al. (2003) \\
\hline MAPK, JNK, ERK, p38 & $\alpha$-particle $\left({ }^{241} \mathrm{Am}\right)$ & $1 \mathrm{~Gy} / 1 \mathrm{fx}$ & $\begin{array}{l}\text { Human bronchial epithelial } \\
\text { cells (Beas-2B) condi- } \\
\text { tioned media on mac- } \\
\text { rophage cells (U937) }\end{array}$ & Fu et al. (2016) \\
\hline \multicolumn{5}{|l|}{ Tumour suppressor } \\
\hline p53 & $\gamma$-ray $\left({ }^{137} \mathrm{Cs}\right)$ & $5-30 \mathrm{~Gy} / 1 \mathrm{fx}$ & Rat cerebral cortex & Raju et al. (2000) \\
\hline \multicolumn{5}{|l|}{ Pro-inflammatory cytokines } \\
\hline IL-1 $\beta$, TNF- $\alpha$, IL-16 & $?$ & ? hypo versus hyper fx & Mouse colon & Barlow et al. (2016) \\
\hline IL- $1 \alpha$, IL- $1 \beta$, TNF- $\alpha$ & $\mathrm{X}$-ray versus $\gamma$-ray $\left({ }^{137} \mathrm{Cs}\right)$ & $7-25 \mathrm{~Gy} / 1 \mathrm{fx}$ & Mouse brain & Hong et al. (1995) \\
\hline IL- $\beta$, TNF- $\alpha$ & $\gamma$-ray $\left({ }^{137} \mathrm{Cs}\right)$ & $10 \mathrm{~Gy} / 1 \mathrm{fx}$ & Rat brain & Lee et al. (2010) \\
\hline IL-6 & $\gamma$-ray $\left({ }^{60} \mathrm{Co}\right)$ & $10 \mathrm{~Gy} / 1 \mathrm{fx}$ & $\begin{array}{l}\text { Human alveolar carcinoma } \\
\text { cells (A549) }\end{array}$ & Gao et al. (2014) \\
\hline IL- $1 \beta$, TNF- $\alpha$ & $\alpha$-particle $\left({ }^{3} \mathrm{He}\right)$ microbeam & $0.5 \mathrm{~Gy} / 1 \mathrm{fx}$ & Human lung fibroblasts & Zhou et al. (2008) \\
\hline IL-6 & $\gamma$-ray $\left({ }^{60} \mathrm{Co}\right.$ or $\left.{ }^{137} \mathrm{Cs}\right)$ & 9-10 Gy/1fx & Mouse plasma and lung & $\begin{array}{l}\text { Van der Meeren et al. } \\
(2003)\end{array}$ \\
\hline TNF- $\alpha$ & $\gamma$-ray $\left({ }^{192} \mathrm{Ir}\right)$ & $10 \mathrm{~Gy} / 1 \mathrm{fx}$ & Rat brain & (Kim et al. 2002) \\
\hline IL- $1 \alpha$, TNF- $\alpha$ & $\gamma$-ray $\left({ }^{137} \mathrm{Cs}\right)$ & $0-35 \mathrm{~Gy} / 1 \mathrm{fx}$ & Mouse brain & Moravan et al. (2011) \\
\hline TNF- $\alpha$ & $\mathrm{X}$-ray & $\begin{array}{r}2-20 \mathrm{~Gy} / 1 \mathrm{fx} \text { versus } \\
10-40 \mathrm{~Gy} / 5-20 \mathrm{fx}\end{array}$ & Mouse brain & Gaber et al.(2003) \\
\hline IL-1 $\alpha$, IL-6 & $\mathrm{X}$-ray & $12 \mathrm{~Gy} / 1 \mathrm{fx}$ & $\begin{array}{l}\text { Mouse lung, bronchial lav- } \\
\text { age fluid, serum }\end{array}$ & Ao et al. (2009) \\
\hline IL-8 & $\alpha$-particle $\left({ }^{238} \mathrm{Pu}\right)$ & $0.036-0.19 \mathrm{~Gy} / 1 \mathrm{fx}$ & Human lung fibroblasts & Narayanan et al. (1999) \\
\hline $\begin{array}{l}\text { IL-1 } \alpha, \text { IL-1 } \beta, \text { IL12p40, } \\
\text { IL-18, TNF- } \alpha, \text { IFN- } \gamma\end{array}$ & $\gamma$-ray $\left({ }^{60} \mathrm{Co}\right)$ & $5-20 \mathrm{~Gy} / 1 \mathrm{fx}$ & $\begin{array}{l}\text { Murine bone marrow- } \\
\text { derived macrophages }\end{array}$ & Liu et al. (2017) \\
\hline \multicolumn{5}{|l|}{ Anti-inflammatory cytokines } \\
\hline TGF- $\beta 1$ & $\gamma$-ray $\left({ }^{192} \mathrm{Ir}\right)$ & $10 \mathrm{~Gy} / 1 \mathrm{fx}$ & Rat brain & Kim et al. (2002) \\
\hline IL-4, IL-5, IL-10 & $\gamma$-ray $\left({ }^{60} \mathrm{Co}\right)$ & $5 \mathrm{~Gy} / 1 \mathrm{fx}$ & Murine splenocytes & Han et al. (2006) \\
\hline \multicolumn{5}{|l|}{ Haematopoietic } \\
\hline EPO, ТPO & $\gamma$-ray $\left({ }^{60} \mathrm{Co}\right)$ & $7.5 \mathrm{~Gy} / 1 \mathrm{fx}$ & Mouse plasma and kidney & $\begin{array}{l}\text { Barshishat-Kupper et al. } \\
\text { (2011) }\end{array}$ \\
\hline G-CSF & X-ray & 12 Gy/1fx & $\begin{array}{l}\text { Mouse lung, bronchial lav- } \\
\text { age fluid, serum }\end{array}$ & Ao et al. (2009) \\
\hline EPO & $\gamma$-ray $\left({ }^{137} \mathrm{Cs}\right)$ & $4 \mathrm{~Gy} / 1 \mathrm{fx}$ & Mouse plasma & Peslak et al. (2012) \\
\hline CSF1, IL-34 & X-ray & $12 \mathrm{~Gy} / 1 \mathrm{fx}$ & $\begin{array}{l}\text { Patient-derived xenografts } \\
\text { (U251, GBM12) }\end{array}$ & Stafford et al. (2016) \\
\hline
\end{tabular}


Table 2 (continued)

\begin{tabular}{|c|c|c|c|c|}
\hline Mediators & Source & Dose/fraction & Tissue niche & References \\
\hline \multicolumn{5}{|l|}{ Prostanoids } \\
\hline $\mathrm{PGE}_{2}$ and $\mathrm{TXA}_{2}$ & $\gamma$-ray $\left({ }^{137} \mathrm{Cs}\right)$ & $35 \mathrm{~Gy} / 1 \mathrm{fx}$ & Mouse brain & Moore et al. (2004) \\
\hline PTGES & $\gamma$-ray $\left({ }^{137} \mathrm{Cs}\right)$ & $0-35$ Gy/1fx & Mouse brain & Moravan et al. (2011) \\
\hline \multicolumn{5}{|l|}{ Growth factors } \\
\hline EGFR & $\gamma$-ray $\left({ }^{137} \mathrm{Cs}\right)$ & $2 \mathrm{~Gy} / 1 \mathrm{fx}$ & $\begin{array}{l}\text { Human breast (MDA- } \\
\text { MB-231) and squamous } \\
\text { carcinoma cells (A431) }\end{array}$ & Dent et al. (2003) \\
\hline EGFR & $\gamma$-ray $\left({ }^{60} \mathrm{Co}\right)$ & $10 \mathrm{~Gy} / 1 \mathrm{fx}$ & $\begin{array}{l}\text { Human alveolar carcinoma } \\
\text { cells (A549) }\end{array}$ & Gao et al. (2014) \\
\hline Basic FGF & $\gamma$-ray $\left({ }^{137} \mathrm{Cs}\right)$ & $10 \mathrm{~Gy} / 1 \mathrm{fx}$ & Rat cerebral cortex & Raju et al. (2000) \\
\hline VEGF & X-ray & $6 \mathrm{~Gy} / 3 \mathrm{fx}$ & Rat cerebral cortex & Jin et al. (2014) \\
\hline G-CSF & X-ray & 12 Gy/1fx & $\begin{array}{l}\text { Mouse lung, bronchial lav- } \\
\text { age fluid, serum }\end{array}$ & Ao et al. (2009) \\
\hline \multicolumn{5}{|l|}{ Chemokines } \\
\hline CXCL10 & $?$ & ? hypo versus hyper fx & $\begin{array}{l}\text { Mouse colon cancer cells } \\
\quad(\text { Colon 38) }\end{array}$ & Barlow et al. (2016) \\
\hline CCL2 & $\gamma$-ray $\left({ }^{137} \mathrm{Cs}\right)$ & $10 \mathrm{~Gy} / 1 \mathrm{fx}$ & Rat brain & Lee et al. (2010) \\
\hline CXCL1 & $\gamma$-ray $\left({ }^{60} \mathrm{Co}\right.$ or $\left.{ }^{137} \mathrm{Cs}\right)$ & 9-10 Gy/1fx & Mouse plasma and lung & $\begin{array}{l}\text { Van der Meeren et al. } \\
(2003)\end{array}$ \\
\hline CCL2 & $\gamma$-ray $\left({ }^{137} \mathrm{Cs}\right)$ & 0-35 Gy/1fx & Mouse brain & Moravan et al. (2011) \\
\hline CXCL1, CCL2, CXCL10 & X-ray & $12 \mathrm{~Gy} / 1 \mathrm{fx}$ & $\begin{array}{l}\text { Mouse lung, bronchial lav- } \\
\text { age fluid, serum }\end{array}$ & Ao et al. (2009) \\
\hline CCL2 & $\gamma$-ray $\left({ }^{60} \mathrm{Co}\right)$ & $5-20 \mathrm{~Gy} / 1 \mathrm{fx}$ & $\begin{array}{l}\text { Murine bone marrow- } \\
\text { derived macrophages }\end{array}$ & Liu et al. (2017) \\
\hline \multicolumn{5}{|l|}{ Adhesion molecules } \\
\hline ICAM-1 & $\mathrm{X}$-ray versus $\gamma$-ray $\left({ }^{137} \mathrm{Cs}\right)$ & $2-25 \mathrm{~Gy} / 1 \mathrm{fx}$ & Mouse brain & Hong et al. (1995) \\
\hline P-selectin, PECAM-1 & $\gamma$-ray $\left({ }^{60} \mathrm{Co}\right.$ or $\left.{ }^{137} \mathrm{Cs}\right)$ & 9-10 Gy/1fx & $\begin{array}{l}\text { Mouse lung endothelial } \\
\text { cells }\end{array}$ & $\begin{array}{l}\text { Van der Meeren et al. } \\
\text { (2003) }\end{array}$ \\
\hline ICAM-1 & $\gamma$-ray $\left({ }^{137} \mathrm{Cs}\right)$ & 0-35 Gy/1fx & Mouse brain & Moravan et al. (2011) \\
\hline ICAM-1 & X-ray & $\begin{array}{r}2-20 \text { Gy/1fx versus } \\
10-40 \text { Gy/5-20fx }\end{array}$ & Mouse brain & Gaber et al. (2003) \\
\hline P-selectin, VCAM-1 & $\gamma$-ray $\left({ }^{137} \mathrm{Cs}\right)$ & $9 \mathrm{~Gy} / 1 \mathrm{fx}$ & Mouse bone marrow & Mazo et al. (2002) \\
\hline \multicolumn{5}{|l|}{ Enzymes } \\
\hline COX-2, iNOS & $\alpha$-particle $\left({ }^{3} \mathrm{He}\right)$ microbeam & $0.5 \mathrm{~Gy} / 1 \mathrm{fx}$ & $\begin{array}{l}\text { Human skin and lung } \\
\text { fibroblasts }\end{array}$ & Zhou et al. (2008) \\
\hline $\mathrm{COX}-2$ & X-ray & $15 \mathrm{~Gy} / 1 \mathrm{fx}$ & $\begin{array}{l}\text { Murine microglial cells } \\
(\mathrm{BV}-2)\end{array}$ & Hwang et al. (2006) \\
\hline COX-2 & $\gamma$-ray $\left({ }^{137} \mathrm{Cs}\right)$ & $35 \mathrm{~Gy} / 1 \mathrm{fx}$ & Mouse brain & Moore et al. (2004) \\
\hline $\begin{array}{l}\text { COX-1, COX-2, HO-1, } \\
\text { caspase-1, GSTP-1, } \\
\text { SOD2 }\end{array}$ & $\gamma$-ray $\left({ }^{137} \mathrm{Cs}\right)$ & $0-35$ Gy/1fx & Mouse Brain & Moravan et al. (2011) \\
\hline $\begin{array}{l}\text { SOD2, GST, GPX and } \\
\text { catalase }\end{array}$ & $\gamma$-ray $\left({ }^{137} \mathrm{Cs}\right)$ & $0.02 \mathrm{~Gy} / \mathrm{fx}$ & $\begin{array}{l}\text { Human lymphoblastoid } \\
\text { cells (AHH-1) }\end{array}$ & Bravard et al. (1999) \\
\hline HO-1,GSTA-2 & $\gamma$-ray $\left({ }^{137} \mathrm{Cs}\right)$ & $2.5-20 \mathrm{~Gy} / 5 \mathrm{fx}$ & $\begin{array}{l}\text { Murine embryo fibroblasts, } \\
\text { fibroblast cells (NIH- } \\
\text { 3T3) and dendritic cells } \\
\text { (DC2.4) }\end{array}$ & McDonald et al. (2010) \\
\hline $\mathrm{HO}-1$ & $\gamma$-ray $\left({ }^{137} \mathrm{Cs}\right)$ & $0.1-2.5 \mathrm{~Gy} / 1 \mathrm{fx}$ & $\begin{array}{l}\text { Mouse macrophages cells } \\
\text { (RAW264.7) }\end{array}$ & Tsukimoto et al. (2010) \\
\hline \multicolumn{5}{|l|}{ Angiogenic/vascular } \\
\hline VEGF & X-ray & $6 \mathrm{~Gy} / 3 \mathrm{fx}$ & Mouse brain & Jin et al. (2014) \\
\hline HIF- $1 \alpha$ and HIF- $2 \alpha$ & $\gamma$-ray $\left({ }^{60} \mathrm{Co}\right)$ & $7.5 \mathrm{~Gy} / 1 \mathrm{fx}$ & Mouse plasma and kidney & $\begin{array}{l}\text { Barshishat-Kupper et al. } \\
\text { (2011) }\end{array}$ \\
\hline
\end{tabular}


Table 2 (continued)

\begin{tabular}{|c|c|c|c|c|}
\hline Mediators & Source & Dose/fraction & Tissue niche & References \\
\hline Basic FGF & $\gamma$-ray $\left({ }^{137} \mathrm{Cs}\right)$ & $10 \mathrm{~Gy} / 1 \mathrm{fx}$ & Rat cerebral cortex & Raju et al. (2000) \\
\hline \multicolumn{5}{|l|}{ Pro-fibrotic } \\
\hline TGF- $\beta 1$ & $\gamma$-ray $\left({ }^{192} \operatorname{Ir}\right)$ & $10 \mathrm{~Gy} / 1 \mathrm{fx}$ & Rat brain & Kim et al. (2002) \\
\hline TGF- $\beta 1$ & Proton $\left({ }^{3} \mathrm{He}\right)$ microbeam & $0.016-0.16 \mathrm{~Gy} / 1 \mathrm{fx}$ & $\begin{array}{l}\text { Human glioblastoma cells } \\
\text { (T98G) }\end{array}$ & Shao et al. (2008) \\
\hline \multicolumn{5}{|l|}{ Acute phase proteins } \\
\hline Alpha 1-antichymotrypsin & $\mathrm{X}$-ray versus $\gamma$-ray $\left({ }^{137} \mathrm{Cs}\right)$ & $25 \mathrm{~Gy} / 1 \mathrm{fx}$ & Mouse brain & Hong et al. (1995) \\
\hline \multicolumn{5}{|l|}{ Hypoxia-sensing proteins } \\
\hline HIF- $1 \alpha$ and HIF- $2 \alpha$ & $\gamma$-ray $\left({ }^{60} \mathrm{Co}\right)$ & $7.5 \mathrm{~Gy} / 1 \mathrm{fx}$ & Mouse plasma and kidney & $\begin{array}{l}\text { Barshishat-Kupper et al. } \\
\text { (2011) }\end{array}$ \\
\hline \multicolumn{5}{|l|}{ Coagulation } \\
\hline $\begin{array}{l}\text { Factors II, V, VII, VIII, } \\
\text { IX, X, XI, XII }\end{array}$ & Proton & $\begin{array}{l}0-2 \text { Gy/1fx high- versus } \\
\text { low-dose rate }\end{array}$ & Ferret plasma & Krigsfeld et al. (2012) \\
\hline $\begin{array}{l}\text { TF, endothelial micropar- } \\
\text { ticles }\end{array}$ & X-ray & $20 \mathrm{~Gy} / 1 \mathrm{fx}$ & Human PBMC & Goldin-Lang et al. (2007) \\
\hline TF, TM & $\gamma$-ray $\left({ }^{60} \mathrm{Co}\right.$ or $\left.{ }^{137} \mathrm{Cs}\right)$ & $9-10 \mathrm{~Gy} / 1 \mathrm{fx}$ & $\begin{array}{l}\text { Mouse plasma and lung } \\
\text { endothelial cells }\end{array}$ & $\begin{array}{l}\text { Van der Meeren et al. } \\
\text { (2003) }\end{array}$ \\
\hline TM, PAR-1 & $\mathrm{X}$-ray & $33.6 \mathrm{~Gy} / 8 \mathrm{fx}$ or $67.2 / 16 \mathrm{fx}$ & $\begin{array}{l}\text { Rat intestinal vascular and } \\
\text { smooth muscle cells }\end{array}$ & Wang et al. (2002) \\
\hline
\end{tabular}

$A P$ activator protein, $C O X$ cyclo-oxygenase, $C R E B$ cyclic adenosine monophosphate responsive element binding protein, $C S F$ colony stimulating factor, $E G F$ epidermal growth factor, $E G R$ early growth response protein, $E P O$ erythropoietin, $F G F$ fibroblast growth factor, $G$ - $C S F$ granulocyte colony stimulating factor, $G M-C S F$ granulocyte/macrophage colony stimulating factor, $G P X$ glutathione peroxidase, $G S T$ glutathione S-transferase, $H I F$ hypoxia-inducible factor, $H O$ heme oxygenase, $I C A M$ intercellular cell adhesion molecule, $N F-\kappa B$ nuclear factor- $\mathrm{BB}, P E C A M$ platelet endothelial cell adhesion molecule, $P G$ prostaglandin, $P I 3 K$ phosphoinositide 3-kinase, $S O D$ superoxide dismutase, $S P$ specificity protein, STAT signal transducer and activator of transcription, TPO thyroid peroxidase, $T X$ thromboxane, VCAM vascular cell adhesion molecule, $V E G F$ vascular endothelial growth factor

ICAM-1, and VCAM-1; ER molecules-BiP, calreticulin as reviewed by Corso et al. (2011). While most of the studies identified were in vitro and in vivo based, few human studies are available which show similar patterns. Irradiated oral mucosa of head and neck cancer patients (60 Gy/30fx) showed increased $\beta 2$ integrin, ICAM- 1 and E-selectin, but not $\beta 1$ integrin or VCAM-1 (Handschel et al. 1999). $100 \mathrm{~Gy}$ ${ }^{137} \mathrm{Cs} \gamma$-irradiation (DR $2 \mathrm{~Gy} / \mathrm{min}$ ) of freshly isolated ovarian tumours increased expression of MHCI and ICAM-1 (Santin et al. 1996). This effect could be further enhanced by priming with cytokines (TNF- $\alpha$ and IFN- $\gamma$ ) before irradiation. Notably though, the level of up-regulation of neo-antigens was different between freshly isolated ovarian tumours and continuous ovarian cell lines, with a more than 5.5-fold greater up-regulation of MHCI in fresh ovarian tumour cells (Santin et al. 1996). This suggests that neo-antigens identified in in vitro and in vivo studies should be confirmed using human tissues before progressing into therapeutic development. Whether the above neo-antigens are also 'revealed' and to what level in patients who receive adjuvant immunotherapy or targeted therapy with RT remains to be delineated.

Of note, DAMPS can also negate the immunogenicity of a tumour following single high-dose IR, but not fractionated IR. Doses of 12-18 Gy to breast and colorectal cancer cell lines induced three prime repair endonuclease (TREX1), impairing type I IFN production (Vanpouille-Box et al. 2017). The downstream effect is suppression of the adaptive immune response and a failure to eliminate the cancer cells. Therein TREX1 has arisen as a potential therapeutic target to enhance the RT-induced immune response to cancer.

\section{Inflammasomes}

NLRP3 and AIM2 inflammasomes contribute to the network of DAMPs, ROS/RNS, ER stress pathways and cytokines activated by IR (Fig. 2). Activation of NLRP3 or AIM2 inflammasomes by cytoplasmic double-stranded DNA induces the release of pro-inflammatory cytokines and activates apoptosis or pyroptosis cell death. Pyroptosis is a pro-inflammatory and lytic form of cell death distinct from apoptosis in that it is dependent on caspase-1 (Bergsbaken et al. 2009).

$0.5-4$ Gy ${ }^{137} \mathrm{Cs}$ total body $\gamma$-irradiation induces a dosedependent increase in inflammasome activation in $\mathrm{M} \phi$, dendritic cells (DCs), natural killer (NK) cells, T-cells, and B-cells (Stoecklein et al. 2015). Following radiation, NLPR3/caspase-1 is activated from day 1 and sustained until 7-day post-radiation (Stoecklein et al. 2015). 10-20 Gy ${ }^{60} \mathrm{Co} \gamma$-irradiated primary cultured bone marrow-derived 
$\mathrm{M} \phi$ showed an increased proportion of pyroptosis, elevated NLRP3 protein expression and caspase- 1 activation, and significantly increased the production of IL- $1 \beta$, IL-18, TNF- $\alpha$, IFN- $\gamma$, IL-1 $\alpha$, IL-12p40 and CCL2 (Liu et al. 2017). 9.5 Gy ${ }^{60} \mathrm{Co} \gamma$-irradiation of C57B1/6 mice induced caspase- 1 cleavage in spleen marginal zone cells (rich in $\mathrm{M} \phi$ and follicular DCs), IL-1 $\beta$, and induced death in the mice (Liu et al. 2017). Akin to the NLRP3 inflammasome, radiation induces activation of the AIM2 inflammasome and caspase-1 mediated pyroptosis (Fernandes-Alnemri et al. 2009; Lamkanfi and Dixit 2014). AIM2/ASC/caspase-1 mediates intestinal epithelial cells and bone marrow cell death from 14.2 Gy subtotal body irradiation (Hu et al. 2016). These data show that radiation-induced activation of either the NLRP3 or AIM2 inflammasomes will trigger immunogenic cell death mechanisms apoptosis and pyroptosis.

\section{Bystander and abscopal effect}

The interconnected inflammatory pathways elicited by irradiation of tumour tissue are summarised in Fig. 2. Ultimately, the tumour response to IR is dictated by the adjacent cells in a multi-cellular response ('bystander effect') and systemically at sites distant to the site of irradiation ('abscopal effect'). Evidence of the bystander effect began with the observation that $0.31 \mathrm{mGy}{ }^{238} \mathrm{Pl} \alpha$-particle irradiation of Chinese hamster ovary cells induced sister chromatid exchanges in $30 \%$ of cells, yet only $1 \%$ of cells were irradiated (Nagasawa and Little 1992). In X-ray irradiation, a dose of 2 Gy elicited a biologically similar effect. This has since been repeated by other laboratories with different radiation sources including heavy ion radiation. ${ }^{3} \mathrm{He}$ single-cell microbeam irradiation of human $\mathrm{T} 98 \mathrm{G}$ glioblastoma cells leads to $40 \%$ of cells demonstrating increased NO levels, whilst only $1 \%$ of cell nuclei were targeted (Shao et al. 2003).

\section{Bystander effect}

Intracellular communication via gap junctions, and intercellular signalling by means of a range of cell-derived soluble factors have been implicated in modulating the bystander effect. These include ROS NO; $\mathrm{O}_{2}{ }^{--}, \mathrm{H}_{2} \mathrm{O}_{2}$ (BurdakRothkamm et al. 2007; He et al. 2012; Narayanan et al. 1997; Shao et al. 2003, 2007, 2008), $\left[\mathrm{Ca}^{2+}\right]_{\mathrm{f}}$ (Shao et al. 2006); second messenger cyclic adenosine monophosphate $(\mathrm{He}$ et al. 2014); cytokines IL- $1 \alpha$, IL-6, IL-8, TGF- $\beta 1$, TNF- $\alpha$ (Burdak-Rothkamm et al. 2007; Dong et al. 2015; Ivanov and Hei 2014a; Narayanan et al. 1999; Shao et al. 2007, 2008; Shareef et al. 2007); prostanoid $\mathrm{PGE}_{2}$ (Zhou et al. 2008); transcription factor NF-кB (Fu et al. 2016; Zhou et al. 2008); enzyme cyclo-oxygenase-2 (COX-2) (Zhou et al. 2005, 2008); tyrosine kinase MAPK and PKC (Baskar et al. 2008; Fu et al. 2016; Zhou et al. 2005); tumour suppressor p53 (He et al. 2011); DNA damage repair ataxia telangiectasia mutated protein (Burdak-Rothkamm et al. 2008; Hagelstrom et al. 2008), ataxia telangiectasia and Rad3-related protein (Burdak-Rothkamm et al. 2007), DNA-dependent protein kinase (Hagelstrom et al. 2008); death receptor ligand soluble TRAIL (Ivanov and Hei 2014a, b; Shareef et al. 2007); and cytochrome c (He et al. 2011, 2012). These modulators initiate cell death or senescence in neighbouring tumours cells. Grid therapy, minibeam/microbeam RT and spatial modulation (delivery of radiation to a treatment area that is divided into several smaller fields) with sharp dose gradients may enable greater tumour cytotoxicity and reduce radiation-induced injury to surrounding healthy tissues by enhancing the bystander effect whilst preserving endothelial cell and surrounding healthy tissue function (Asur et al. 2015; Mackonis et al. 2007; Trainor et al. 2012; Zhang et al. 2014).

\section{Abscopal effect}

While the local bystander effect is being touted as a way of evoked greater tumouricidal activity while preserving healthy normal tissue, by way of reducing radiation-induced injury to endothelial and parenchymal cells, the systemic abscopal effect has received greater scepticism with primarily anecdotal case study reports and few preclinical studies. Mole first described the abscopal effect as a radiationinduced tumour effect "at a distance from the irradiated volume but within the same organism" (Mole 1953). A recent meta-analysis study of the preclinical data available to date conclude that the abscopal effect is linked to the biological effective dose of radiation, whereby a dose of 60 Gy has a probability of $50 \%$ for observing the abscopal effect (Marconi et al. 2017). Perhaps the greatest body of support for the abscopal effect comes from a 2015 proof-ofprinciple clinical trial. Patients with solid metastatic cancer received $35 \mathrm{~Gy} / 10 \mathrm{fx} \mathrm{X}$-ray radiation to one metastatic lesion and adjuvant GM-CSF $\left(125 \mu \mathrm{g} / \mathrm{m}^{2}\right)$, before repeating the regimen on a second metastatic lesion. Of the 41 patients enrolled, 11 patients achieved abscopal response denoted as a $30 \%$ reduction in the maximal tumour diameter in the best responding lesion (Golden et al. 2015).

Both the abovementioned preclinical and clinical studies involved a range of tumour types breast, colon, lung, fibrosarcoma, pancreas, melanoma, head and neck cancer (Marconi et al. 2017), non-small cell lung, breast and thymic (Golden et al. 2015) indicating that the abscopal effect is plausible and can be elicited in many cancer types. A similar meta-analysis encompassing case reports, a retrospective study and preclinical data surmised that issues concerning radiation and immunotherapy dosage, timing, patient selection and toxicity need to be resolved before the abscopal effect can become clinically relevant (Reynders et al. 2015). 
The abscopal effect is mediated by antigen presenting cells DCs, $\mathrm{M} \phi$ and CTLs activated by inflammatory mediators (e.g. cytokines, DAMPs, ROS/RNS) from the irradiated tumour microenvironment and travelling to tumourdraining lymph nodes and distant non-irradiated sites. In the lymph nodes, DCs and $\mathrm{M} \phi$ activate effector T-cell populations through MHC presentation and secretion of the soluble tumour modulating molecules described for the bystander effect above. Following activation and expansion in the lymph nodes CTL, NK cells and Th-cell populations travel to distant tumour sites and elicit a pro-inflammatory response leading to reductions in tumour growth at non-irradiated sites (Demaria and Formenti 2016; Grass et al. 2016; Hu et al. 2017; Ng and Dai 2016; Siva et al. 2015). This effect is enhanced by PDL-1/PD-1 immunotherapy which blocks the immunosuppressive signal from the tumour cells, enabling a persistent pro-inflammatory and tumourcidal microenvironment (Park et al. 2015). A summary of preclinical studies demonstrating the abscopal effect following combined RT and immunotherapy can be found in a recent review by Ngwa et al. (2018).

\section{Inflammatory and immune system cellular response}

To date this review has covered inflammatory mediators and cell death mechanisms initiated and elicited by IR. While immune cell populations also contribute ROS/RNS, DAMPS, cytokines/chemokines and inflammasome activation in the irradiated tumour microenvironment (Fig. 3), this section focusses on the effect of IR on innate and adaptive immune cell recruitment, expansion, polarisation/differentiation, and functions not already addressed elsewhere in the review.

\section{Innate immune cells}

IR actives resident $M \phi$ (including microglia) via ROS/RNS, DAMPS, cytokines/chemokines and stimulates the release of haematopoietic progenitors from the bone marrow and the infiltration of PMN, Mø and DCs in the tumour microenvironment (Fig. 3). Low-dose total body X-ray irradiation $(0.075 \mathrm{~Gy})$ induces the recruitment of haematopoietic progenitor cells from the bone marrow into peripheral blood at $48-72 \mathrm{~h}$ of post-radiation. This is mediated by the release of G-CSF and GM-CSF ( $\mathrm{Li}$ et al. 2004). Following 4 Gy $\mathrm{X}$-ray irradiation, there was transient production of the PMN chemoattractants CXCL2 and CXCL8, and the infiltration of PMNs (Uchimura et al. 2000). $\mathrm{M} \phi$ are recruited into irradiated tumour tissue at both acute and late stages through $\mathrm{M} \varnothing / \mathrm{M} \phi$ chemoattractants CCL2, CCL5, CCL7, CCL8, CXCL12, VEGF and CSF-1 (Kioi et al. 2010; Kozin et al. 2010; Sica et al. 2008; Xu et al. 2013). As for PMN and Mø, immature DCs are recruited by a range of chemokines generated during pro-inflammatory response in the irradiated tumour microenvironment including CCL3, CCL4, CCL7, CCL13, CCL15, CCL20, CCL5, CCLZS and CXCL12 (Caux et al. 2000; Kioi et al. 2010; Kozin et al. 2010; Vicari et al. 2004).

Radiation polarises $\mathrm{M} \phi$ to pro-inflammatory $\mathrm{M} \phi$ type 1 (M1) and immunosuppressive $\mathrm{M} \phi$ type 2 (M2) phenotypes.

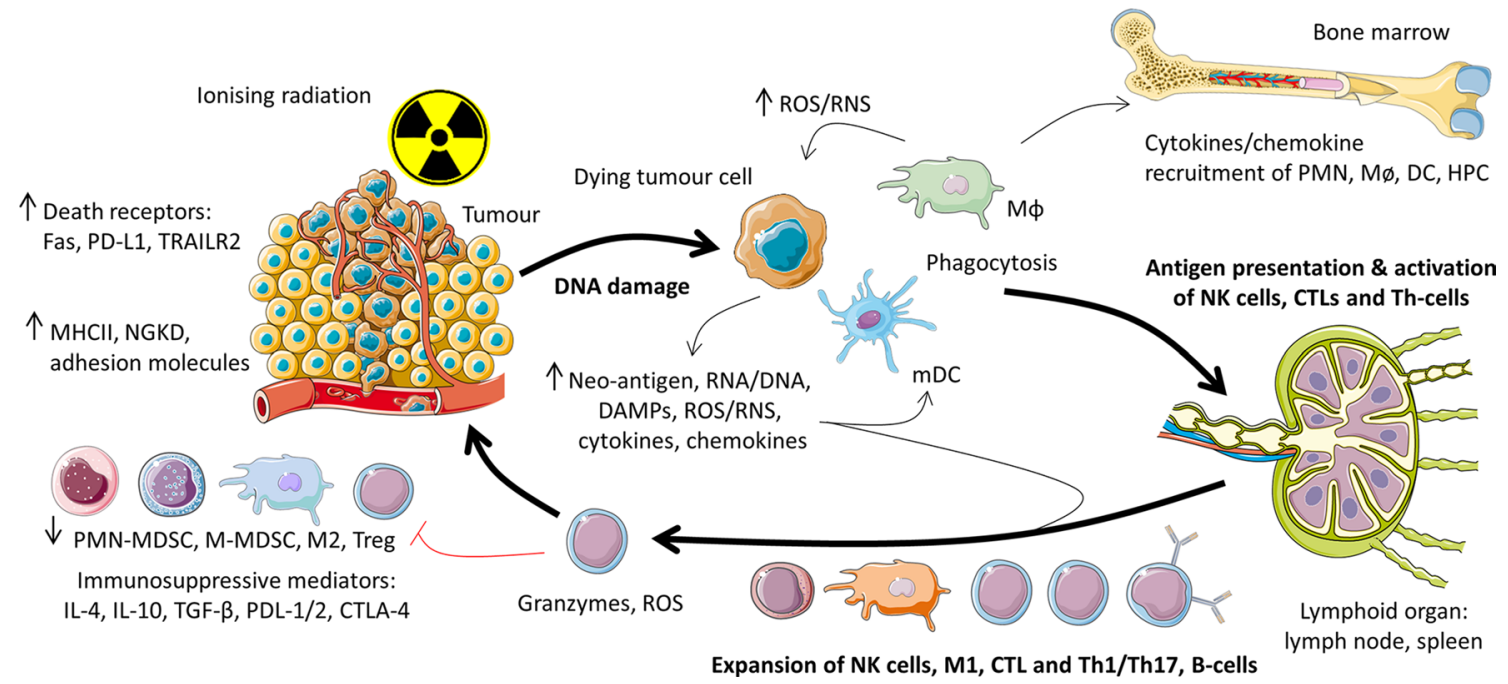

Fig. 3 Role of the innate and adaptive immune cells following the irradiation of tumour cells. HPC haematopoietic progenitor cells. Bold text and arrows denote the essential pathway of RT-induced immune activation by (i) direct or indirect (ROS-RNS-mediated)
DNA damage, (ii) antigen presentation and activation by DCs, and (iii) expansion and specificity of the adaptive immune response. Image modified from (Kamrava et al. 2009) and prepared using Servier Medical Art (https://smart.servier.com/) 
Following radiation, $\mathrm{M} \phi$ activate $\mathrm{p} 53$-dependent ROS/ RNS pathways (Lorimore et al. 2001), and the COX-2 pathway mediated by TNF- $\alpha$ and FasL (Rastogi et al. 2012b). Tumour-associated $\mathrm{M} \phi$ (TAMs) in irradiated tissue polarise to a pro-inflammatory M1 phenotype (iNOS ${ }^{+}$), produce ROS/RNS and the secretion of pro-inflammatory cytokines IL-6, IL-12, TNF- $\alpha$ and IFN- $\gamma$ (Farooque et al. 2016; Klug et al. 2013; Rastogi et al. 2013; Tsai et al. 2007). Yet, tumour cells and the irradiated tumour microenvironment also produce M2 activators (IL-4, IL-10, IL-13, TGF- $\beta$, and PGE 2 ). TAMs in the irradiated tumour microenvironment express higher levels of M2 markers (Arg-1, COX-2), and promote early tumour growth in vivo (Tsai et al. 2007). TAMs phagocytose radiation-induced apoptotic cells and debris. This leads to their activation, marked by membrane ruffing, increased lysosome number and size, increased $\mathrm{M} \phi$ lysosomal acid $\beta$-galactosidase activity, and iNOS/ROS/RNS activity (Lorimore et al. 2001). Radiation-induced apoptosis of murine L1210 leukaemic cells or human Jurkat T-cells increased the engulfment/phagocytosis by M1s fourfold (and to a lesser extent M2) (Rastogi et al. 2013). Engulfment of apoptotic cells further polarises the M1 versus M2 phenotypes.

Fractionation of radiation changes the timeline for M1 and M2 involvement. Following a 25 Gy single fraction X-ray dose (DR 2-3 Gy/min) in murine TRAMP-C1 prostate cells, M2 markers (Arg-I and COX-2) increased transiently at $24 \mathrm{~h}$ before a larger persistent infiltration developed from day 3 (Tsai et al. 2007). M1 marker (iNOS) increased from day 3 and progressively increased up to 3 -week post-irradiation. In contrast, fractionated radiation of $60 \mathrm{~Gy} / 15 \mathrm{fx}$ saw a similar increase in M2 up to 5-day post-irradiation, but M1 presence was delayed-appearing after ten fractions (2 weeks post-irradiation) (Tsai et al. 2007). Some care needs to be taken when translating murine model to human studies. In addition to strain differences in radiosensitivity, oxidative stress response, DNA repair, apoptosis and cytokine production, differences in immune regulation are also noted (Ao et al. 2009; Haston et al. 2005). In vivo, murine 4 Gy $\gamma$-radiation exposure is associated with genotype-dependent bone marrow-derived $\mathrm{M} \phi$ activation. Radiation further induced a CBA/Ca M1 phenotype (increased iNOS, IL-6, TNF- $\alpha$, ROS/RNS) and C57B1/6 M2 phenotype (reduced iNOS, increased arginase and TGF- $\beta$ ) (Coates et al. 2008; Rastogi et al. 2012a). In patients, 72-86Gy irradiation of extratumoural ocular tissue or gliomas with ${ }^{60} \mathrm{Co},{ }^{106} \mathrm{Ru}$ or ${ }^{125} \mathrm{I}$ heavy ions increased $\mathrm{CD} 68^{+} \mathrm{M} \phi$ infiltrates, however M1/M2 subtype was not delineated (Julow et al. 2007; Toivonen and Kivela 2012).

Akin to $\mathrm{M} \phi$, DCs represent a spectrum of cell phenotypes which are involved in the tumour immune response and altered by IR. These include myeloid DCs, plasmacytoid DCs, monocytic myeloid-derived suppressor cells
(M-MDSC) and PMN-MDSCs. $20 \mathrm{~Gy} / 1 \mathrm{fx}$ irradiation of B16 melanoma tumour-bearing mice determined that radiation increased $\mathrm{CD} 11 \mathrm{c}^{+} \mathrm{mDC}$ migration to tumour-draining lymph nodes, and promoted their maturation (up-regulation of MHCII) (Lee et al. 2009). No effect was seen on plasmacytoid DCs. While the cell-specific markers of MDSCs are still being elucidated (Bronte et al. 2016), this heterogeneous class of DCs provides immune suppression of Th-cells and CTLs in the tumour microenvironment (Movahedi et al. 2008; Solito et al. 2012). Radiation-induced cell death externalises DAMPs such as HMGB1, ATP and calreticulin on the tumour cells surface and the release of ROS/RNS (Fig. 3) (Frey et al. 2014; Inoue and Tani 2014; Lotze et al. 2007). These promote DC maturation and the activation of effector T-cell responses via DC-derived co-stimulatory molecules and cytokines (Tan et al. 2013). Radiation-induced ROS/ RNS enhance the immunosuppressive activity of MDSC via up-regulation of the Keap1/nuclear factor erythroid2-related factor-2 sensor of oxidative stress (Beury et al. 2016). Following irradiation, murine 1D8 ovarian carcinoma cells up-regulate the activation marker CD80 and suppress $\mathrm{CD} 4{ }^{+} \mathrm{CD} 25^{+}$regulatory T-cells (Tregs) via engagement of CD152 (CTLA-4) (Yang et al. 2006). M-MDSC immunosuppression of T-cell responses is dependent on M-MDSC STAT1 and the production of IFN- $\gamma$ and NO, while PMNMDSC immunosuppressive activity requires IFN- $\gamma$ (Movahedi et al. 2008). High-dose X-ray radiation (30 Gy/1fx; DR $1.21 \mathrm{~Gy} / \mathrm{min}$ ) of CT26 or MC38 colon tumour-bearing mice can overcome the MDSC suppressive activity and returns the CTL population required for tumour eradication (Filatenkov et al. 2015). This change was driven by $\mathrm{CD} 8^{+}$DCs crosspresentation and IFN- $\gamma$ secretion, and CD40L expressing Th-cells. These highlight that IR is a critical activator of innate immune cells for the macrophagic removal of apoptotic cells, drive the antigen-specific response to tumour cells through DC antigen presentation, and to alleviate immunosuppressive signalling by MDSC in the tumour microenvironment (Fig. 3).

\section{Adaptive immune cells}

Polarisation and activation of M $\phi$ and DCs by DAMPs and ROS/RNS in the irradiated tumour environment are critical for driving the adaptive immune response (Frey et al. 2014; Inoue and Tani 2014; Lotze et al. 2007). Upon activation, $\mathrm{M} \phi$ and DCs migrate to the tumour-draining lymph nodes and present tumour-specific antigen on MHCI or MHCII molecules to T-cells and B-cells (Fig. 3).

IR can induce the expression of neo-antigens by tumours cells which can activate NK cells directly (NKGD and MHCI), or indirectly through DAMPs and ROS/RNS released from dying tumour cells. 15 Gy X-ray irradiation of murine B16 melanoma tumour-bearing mice increased the 
proportion of apoptotic and necrotic tumour cells, as well as B-cells, NK cells, Th-cells and CTLs in tumour-draining lymph nodes when irradiated in conjunction with hyperthermia $\left(41.5^{\circ} \mathrm{C}\right.$ for $1 \mathrm{~h}$ ) (Finkel et al. 2016). In canine osteosarcoma, 10-20 Gy irradiation dose-dependently increased NK cytotoxicity (Canter et al. 2017). Low-dose RT (2 Gy) was found to prime NK cells and increased NK cell number and cytotoxicity of tumours following autologous adoptive transfer into dogs (Canter et al. 2017).

Akin to NK cells, CTLs are a critical tumourcidal cell through their expression of death receptor and the release of granules containing perforin and granzymes. $30 \mathrm{~Gy} / 1 \mathrm{fx}$ radiation of murine colon tumours enhanced the CTL infiltrate 3.7-fold and is dependent on antigen cross-presentation by CD8 ${ }^{+}$DCs and IFN- $\gamma$ (Filatenkov et al. 2015). Fractionated RT of $30 \mathrm{~Gy} / 10$ fx reduced $\mathrm{CD} 8^{+}$T-cell infiltrates 2.4-fold compared to non-irradiated animals and increased fatality. Murine B16 melanomas irradiated with $20 \mathrm{~Gy} / 1 \mathrm{fx}$ X-ray reduced tumour size by $\sim 30 \%$ and increased survival. This effect required CTLs and the migration of CD11 $\mathrm{c}^{+}$DCs to draining lymph nodes to prime T-cells (Lee et al. 2009). Of note, this study went on to demonstrate that chemotherapy abolished DC-mediated priming of T-cells and ablated the RT-induced anti-metastatic effect of CTLs, and fractionated $20 \mathrm{~Gy} / 4 \mathrm{fx}$ failed to induced tumour regression (Lee et al. 2009). The authors speculated that fractionated RT may kill off tumour infiltrating CTLs, and raised the question of the relative biological effectiveness of $20 \mathrm{~Gy} / 1 \mathrm{fx}$ versus $20 \mathrm{~Gy} / 4 \mathrm{fx}$ in activating the inflammatory/immune response.

Th-cells comprise pro-inflammatory (Th1 and Th17), anti-inflammatory (Th2) and immunosuppressive subsets (Treg). The former subsets play a role in tumour eradication, while Tregs support tumour growth principally through the secretion of TGF- $\beta$ which suppresses pro-inflammatory and tumourcidal immune cell subsets (Chen et al. 2005). In addition, radiation increases Treg hydrolysis of the proinflammatory DAMP signal ATP into immunosuppressive/ negative feedback signal adenosine through induced expression of cell surface ecto-nucleotidases (CD39 and CD73) (Mandapathil et al. 2009; Wennerberg et al. 2015). In general, TBI or local irradiation increases the Treg population in mice and humans (Billiard et al. 2011; Kachikwu et al. 2011; Schaue et al. 2008, 2012b; Tomura et al. 2010), though the converse is noted in some studies (Cao et al. 2009; Wennerberg et al. 2015).

In the other Th-cells populations 2.5 Gy X-ray TBI (DR $1.3 \mathrm{~Gy} / \mathrm{min}$ ) increased Th2 cells from day 5 and Treg and Th17 cells from day 8 post-irradiation, while Th1 cells and IFN- $\gamma$ production was reduced (Zheng et al. 2015). This appears to be driven by radiation-induced alterations in transcription factor expression. $5 \mathrm{~Gy}{ }^{60} \mathrm{Co}$ irradiation upregulated Th2 transcription factors c-MAf and GATA-3 and down-regulated mRNA interferon regulatory factor-1 and IFN- $\gamma$ mRNA and Th1 transcription factors STAT1 and STAT4 phosphorylation (Han et al. 2006). Murine 18 Gy whole thorax X-ray irradiation (DR $0.54 \mathrm{~Gy} / \mathrm{min}$ ) leads to changes in T-cell populations at $6 \mathrm{~h}, 24 \mathrm{~h}$ and 7 days in lung tissue, with Th1 and Th17 populations increased in lung tissue but lower in the bronchoalveolar lavage fluid (Paun et al. 2015). Notably strain dependent differences were observed. The difference in Th-cell populations are partly indicated by the radiosensitivity of the cell subsets to radiation mediated by p53-dependent cell death (Yao et al. 2011). NK cells, naive T-cells and B-cells is highly radiosensitive, while effector T-cells and NK/T-cells, are more radioresistant (Belka et al. 1999; Kachikwu et al. 2011; Qu et al. 2010; Yao et al. 2011). Of the effector T-cell populations, Th-cells are more radioresistant than CTLs (Yao et al. 2011). However, it may equally be the CTL:Th $\left(\mathrm{CD}^{+}: \mathrm{CD}^{+}\right)$ratio and diversity of the TCR repertoire, rather than inherent differences in T cell radiosensitivity, that is critical in the elimination of cancer cells. This is highly relevant when considering which model to use for pre-clinical studies of combined RT and immunotherapy (Rudqvist et al. 2018).

B-cells are highly radiosensitive and have a diminished capacity for antigen presentation and antibody production after irradiation. Localised $26 \mathrm{~Gy} / 13 \mathrm{fx}$ irradiation of patients with seminoma resulted in a 5.7-fold and 11-fold decrease in $\mathrm{CD} 19^{+} \mathrm{B}$-cells after $7 \mathrm{fx}$ and $13 \mathrm{fx}$, respectively (Belka et al. 1999). B-cell numbers remained 2.4-fold lower than baseline levels up to 4 months after RT. B-cells exposed to $10-33 \mathrm{~Gy}$ ${ }^{137} \mathrm{Cs} \gamma$-radiation show deficits in antigen presentation and activation of T-cells, despite displaying functional MHCII (Ashwell et al. 1988) and increased expression of the B-cell antigen (CD20) (Kunala and Macklis 2001). Occupational radiation exposure of miners to ${ }^{222} \mathrm{Rn}$ reduced immunoglobulin (Ig) IgG and IgM serum levels after 1 year, but after 2 years IgG increased and exceeded the baseline levels. IgA levels did not change. The hypogammaglobulinemic period (low $\mathrm{IgG}$ ) was followed by an increased in respiratory tract infections (Andrlikova et al. 1975). Similar changes to serum antibody levels have been observed at 5-15 years of postirradiation (Wagner et al. 1978). Changes in Ig production are sensitive to IR and have implications for opportunistic infections as well as cancer patients with comorbid autoimmune disorders (Andrlikova et al. 1975).

\section{Effect of radiation delivery on the immune response}

The effect of IR on inflammation and the immune response is dictated by the radiation type, dose, DR, intensity/fractionation, delivery method, field size, and total cumulative dose. In this review, these have been highlighted where available in the literature. Further elucidation of how the 
above factors alter the relative biological effectiveness of IR on different cancers is needed (Fig. 4), bearing in mind that the radiation total or cumulative dose is in itself dependent on the indication, site of tumour, cancer subclassification, tissue/organ radiosensitivity and the patient's performance status.

While the mechanism remains to be fully elucidated Flash $\mathrm{RT}$, the use of ultra-high DR, is an interesting prospect to further reduce the normal tissue toxicity and maintain tissue function (Durante et al. 2018). Thoracic IR of mice using 15 Gy conventional X-ray (DR $1.8 \mathrm{~Gy} / \mathrm{min}$ ) or $20 \mathrm{~Gy}$ Flash RT (DR $>2400 \mathrm{~Gy} / \mathrm{min}$; pulse rate $<500 \mathrm{~ms}$ ) provided comparable lung tumour control, but Flash RT produced fewer fibrotic lesions (Favaudon et al. 2014). In a similar study, 10 Gy murine whole brain FLASH RT (DR > $6000 \mathrm{~Gy} / \mathrm{min}$; pulse rate $1 \mu \mathrm{s}$ ) preserved spatial memory and hippocampal neurogenesis when compared to conventional RT (6 Gy/ min) (Montay-Gruel et al. 2017). The effect was absent if $\mathrm{DR}<1800 \mathrm{~Gy} / \mathrm{min}$ were used.

While in vitro and in vivo studies utilise the clinical radiation dose/fractionation, the biological implication of DR and differences in the radiosensitivity $(\alpha / \beta$ ratio) of the cell line used in the research, relative to the patient tumour, needs to be considered. For example, the 1.8-2 Gy per fraction regimen was based on human prostate cancer cells having a low $\alpha / \beta$ ratio. Assessment of 5,969 human primary prostate cancers shows an $\alpha=0.009-0.061 \mathrm{~Gy}(-1)$ and an $\alpha / \beta=0.9$ to $2.2 \mathrm{~Gy}$ (Miralbell et al. 2012), while prostate cancer cell lines demonstrate an $\alpha=0.09-0.35 \mathrm{~Gy}((-1)$, and the $\alpha / \beta=1.09$ to $6.29 \mathrm{~Gy}$ (Carlson et al. 2004). If not taken into consideration, the wider range of $\alpha / \beta$ ratio in cell lines may have

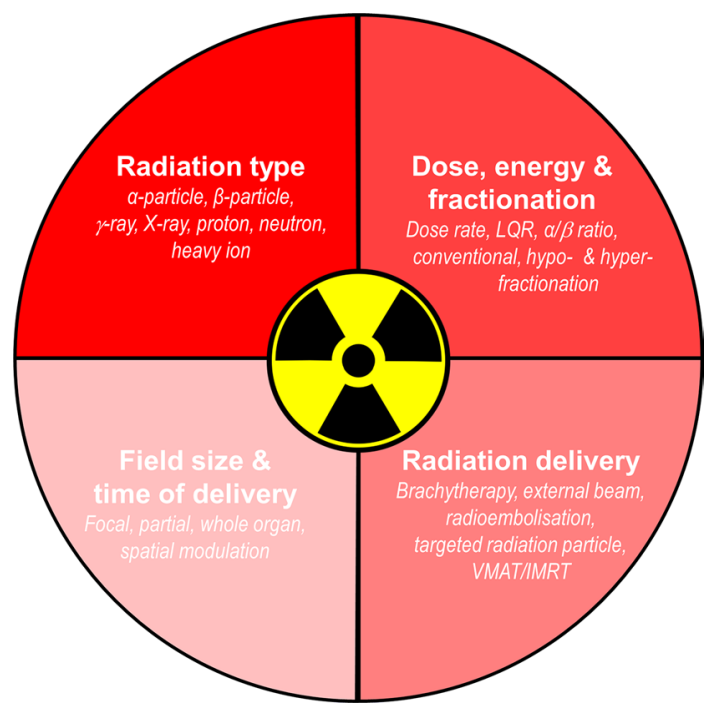

Fig. 4 Aspects of radiation delivery that modulate the inflammatory/ immune response a significant bearing on the interpretation of radiationinduced modulation of the inflammatory/immune response and relative biological effectiveness of different regimens, and ultimately translation of the data to the clinical setting.

\section{Concluding remarks}

It is clear that IR initiates and modulates the inflammatory and immune response through a range of soluble and cellderived factors in the tumour microenvironment. Evident from this review, greater detail in the reporting of radiation type, dose, DR and validation strategies are appearing in manuscripts. However, a couple of changes could be made to existing strategies to provide greater understanding of the inflammatory and immune response to IR, which will have an impact on patient survival in the next 5 years.

Where feasible, serial biopsies should be included in clinical trials to assess not only longitudinal tumour morphological characteristics (Ki67, vascularity, changes in subtype due to cellular changes) but also the changing immune response in the tumour microenvironment before, during and after RT with/out adjuvant therapies, to advise where therapeutic regimens could be improved. This will identify those patients who do and do not respond to a treatment regimen and guide the most appropriate selection of targeted therapies and immunotherapies in relevant patient populations.

While RT-induced immune-related adverse events are beyond the scope of this review, it should be mentioned that a body of evidence is emerging for cardiotoxicity from thoracic RT and combined RT with anti-PD-1 immunotherapy or chemotherapy regimens (Contreras et al. 2018; Du et al. 2018) and highlights the need for greater understanding of the acute and long-term adverse effects of RT/immunotherapy in both tumour and non-tumour tissue compartments. In the preclinical setting, the availability of preclinical irradiators that utilise the clinical technology and treatment planning systems, SARRP ${ }^{\mathrm{TM}}$ by Xstrahl LifeSciences and RAD SmART ${ }^{\mathrm{TM}}$ by Precision X-ray, will improve our understanding of RT-induced immune-related adverse events, as well as the accuracy and reproducibility of RT performed but only if radiobiology/radiooncology principles are also applied, such as the radiosensitivity $\alpha / \beta$ ratio, beam arrangement, and tumour and target volumes.

Finally, it remains to be seen whether activation of bystander effects using spatially modulated fields, and/or harnessing the abscopal effect, are viable treatment strategies. How these and different types of radiation, and combined adjuvant targeted-therapy and immunotherapy influences the inflammatory and immune response needs to be further explored and integrated into clinical practice. 
Acknowledgements K. McKelvey is supported by Sydney NeuroOncology Group, Sydney Vital Translational Cancer Centre, and the Matt Callander Beanie for Brain Cancer HMRI Fellowship funded by the Mark Hughes Foundation; and A. Hudson by Sydney NeuroOncology Group.

\section{Compliance with ethical standards}

Conflict of interest On behalf of all authors, the corresponding author states that there is no conflict of interest.

Open Access This article is distributed under the terms of the Creative Commons Attribution 4.0 International License (http://creativeco mmons.org/licenses/by/4.0/), which permits unrestricted use, distribution, and reproduction in any medium, provided you give appropriate credit to the original author(s) and the source, provide a link to the Creative Commons license, and indicate if changes were made.

\section{References}

Aita VM, Liang XH, Murty VVVS, Pincus DL, Yu W, Cayanis E, Kalachikov S, Gilliam TC, Levine B (1999) Cloning and genomic organization of Beclin 1, a candidate tumor suppressor Ggene on chromosome 17q21. Genomics 59:59-65

Andrlikova J, Wagner V, Palek V (1975) Investigation of immunoglobulin (IgG, IgA, IgM) levels in the blood serum of uranium miners after higher and lower exposure to ionizing radiation. Strahlentherapie 149:212-218

Ao X, Zhao L, Davis MA, Lubman DM, Lawrence TS, Kong FM (2009) Radiation produces differential changes in cytokine profiles in radiation lung fibrosis sensitive and resistant mice. J Hematol Oncol 2:6

Ashwell JD, Jenkins MK, Schwartz RH (1988) Effect of gamma radiation on resting B lymphocytes. II. Functional characterization of the antigen-presentation defect. J Immunol 141:2536

Asur R, Butterworth KT, Penagaricano JA, Prise KM, Griffin RJ (2015) High dose bystander effects in spatially fractionated radiation therapy. Cancer Lett 356:52-57

Avraham T, Yan A, Zampell JC, Daluvoy SV, Haimovitz-Friedman A, Cordeiro AP, Mehrara BJ (2010) Radiation therapy causes loss of dermal lymphatic vessels and interferes with lymphatic function by TGF- $\beta 1$-mediated tissue fibrosis. Am J Physiol Cell Physiol 299:C589-C605

Barlow ML, Battaglia N, Gerber SA, Lord EM (2016) Hypofractionated radiotherapy treatment preserves immune function and improves tumor control vs. hyperfractionated treatment. J Immunol 196:213.213

Barshishat-Kupper M, Mungunsukh O, Tipton AJ, McCart EA, Panganiban RA, Davis TA, Landauer MR, Day RM (2011) Captopril modulates hypoxia-inducible factors and erythropoietin responses in a murine model of total body irradiation. Exp Hematol 39:293-304

Baskar R, Balajee AS, Geard CR, Hande MP (2008) Isoform-specific activation of protein kinase $\mathrm{c}$ in irradiated human fibroblasts and their bystander cells. Int J Biochem Cell Biol 40:125-134

Belka C, Ottinger H, Kreuzfelder E, Weinmann M, Lindemann M, Lepple-Wienhues A, Budach W, Grosse-Wilde H, Bamberg M (1999) Impact of localized radiotherapy on blood immune cells counts and function in humans. Radiother Oncol 50:199-204

Bergsbaken T, Fink SL, Cookson BT (2009) Pyroptosis: host cell death and inflammation. Nat Rev Microbiol 7:99-109
Beury DW, Carter KA, Nelson C, Sinha P, Hanson E, Nyandjo M, Fitzgerald PJ, Majeed A, Wali N, Ostrand-Rosenberg S (2016) Myeloid-derived suppressor cell survival and function are regulated by the transcription factor Nrf2. J Immunol 196:3470-3478

Billiard F, Buard V, Benderitter M, Linard C (2011) Abdominal gamma-radiation induces an accumulation of function-impaired regulatory $\mathrm{T}$ cells in the small intestine. Int $\mathrm{J}$ Radiat Oncol Biol Phys 80:869-876

Bravard A, Luccioni C, Moustacchi E, Rigaud O (1999) Contribution of antioxidant enzymes to the adaptive response to ionizing radiation of human lymphoblasts. Int J Radiat Biol 75:639-645

Bronte V, Brandau S, Chen S-H, Colombo MP, Frey AB, Greten TF, Mandruzzato S, Murray PJ, Ochoa A, Ostrand-Rosenberg S, Rodriguez PC, Sica A, Umansky V, Vonderheide RH, Gabrilovich DI (2016) Recommendations for myeloid-derived suppressor cell nomenclature and characterization standards. Nat Commun 7:12150

Buatti JM, Rivero LR, Jorgensen TJ (1992) Radiation-induced DNA single-strand breaks in freshly isolated human leukocytes. Radiat Res 132:200-206

Burdak-Rothkamm S, Short SC, Folkard M, Rothkamm K, Prise KM (2007) ATR-dependent radiation-induced gamma H2AX foci in bystander primary human astrocytes and glioma cells. Oncogene 26:993-1002

Burdak-Rothkamm S, Rothkamm K, Prise KM (2008) ATM acts downstream of ATR in the DNA damage response signaling of bystander cells. Can Res 68:7059-7065

Campisi J, Fagagna FA (2007) Cellular senescence: when bad things happen to good cells. Nat Rev Mol Cell Biol 8:729

Cann KL, Hicks GG (2006) Absence of an immediate G1/S checkpoint in primary MEFs following gamma-irradiation identifies a novel checkpoint switch. Cell Cycle 5:1823-1830

Canter RJ, Grossenbacher SK, Foltz JA, Sturgill IR, Park JS, Luna JI, Kent MS, Culp WTN, Chen M, Modiano JF, Monjazeb AM, Lee DA, Murphy WJ (2017) Radiotherapy enhances natural killer cell cytotoxicity and localization in pre-clinical canine sarcomas and first-in-dog clinical trial. J Immunother Cancer 5:98

Cao M, Cabrera R, Xu Y, Liu C, Nelson D (2009) Gamma irradiation alters the phenotype and function of CD4+ CD25+ regulatory T cells. Cell Biol Int 33:565-571

Carlson DJ, Stewart RD, Li XA, Jennings K, Wang JZ, Guerrero M (2004) Comparison of in vitro and in vivo alpha/beta ratios for prostate cancer. Phys Med Biol 49:4477-4491

Caux C, Ait-Yahia S, Chemin K, de Bouteiller O, Dieu-Nosjean MC, Homey B, Massacrier C, Vanbervliet B, Zlotnik A, Vicari A (2000) Dendritic cell biology and regulation of dendritic cell trafficking by chemokines. Springer Semin Immunopathol 22:345-369

Chakraborty M, Abrams SI, Camphausen K, Liu K, Scott T, Coleman CN, Hodge JW (2003) Irradiation of tumor cells up-regulates Fas and enhances CTL lytic activity and CTL adoptive immunotherapy. J Immunol 170:6338-6347

Chaurasia M, Bhatt AN, Das A, Dwarakanath BS, Sharma K (2016) Radiation-induced autophagy: mechanisms and consequences. Free Radical Res 50:273-290

Chen ML, Pittet MJ, Gorelik L, Flavell RA, Weissleder R, von Boehmer H, Khazaie K (2005) Regulatory T cells suppress tumorspecific CD8 T cell cytotoxicity through TGF-beta signals in vivo. Proc Natl Acad Sci USA 102:419-424

Chen FH, Chiang CS, Wang CC, Tsai CS, Jung SM, Lee CC, McBride WH, Hong JH (2009) Radiotherapy decreases vascular density and causes hypoxia with macrophage aggregation in TRAMP-C1 prostate tumors. Clin Cancer Res 15:1721-1729

Coates PJ, Rundle JK, Lorimore SA, Wright EG (2008) Indirect macrophage responses to ionizing radiation: implications for genotype-dependent bystander signaling. Can Res 68:450-456 
Contreras JA, Lin AJ, Weiner A, Speirs C, Samson P, Mullen D, Campian J, Bradley J, Roach M, Robinson C (2018) Cardiac dose is associated with immunosuppression and poor survival in locally advanced non-small cell lung cancer. Radiother Oncol. https:// doi.org/10.1016/j.radonc.2018.05.017

Corso CD, Ali AN, Diaz R (2011) Radiation-induced tumor neoantigens: imaging and therapeutic implications. Am J Cancer Res 1:390-412

Dadey DYA, Kapoor V, Khudanyan A, Urano F, Kim AH, Thotala D, Hallahan DE (2016) The ATF6 pathway of the ER stress response contributes to enhanced viability in glioblastoma. Oncotarget 7:2080-2092

Deckbar D, Stiff T, Koch B, Reis C, Lobrich M, Jeggo PA (2010) The limitations of the G1-S checkpoint. Can Res 70:4412-4421

Demaria S, Formenti SC (2016) Can abscopal effects of local radiotherapy be predicted by modeling $\mathrm{T}$ cell trafficking? J ImmunoTher Cancer 4:29

Dent P, Yacoub A, Contessa J, Caron R, Amorino G, Valerie K, Hagan MP, Grant S, Schmidt-Ullrich R (2003) Stress and radiation-induced activation of multiple intracellular signaling pathways. Radiat Res 159:283-300

Dong C, He M, Tu W, Konishi T, Liu W, Xie Y, Dang B, Li W, Uchihori Y, Hei TK, Shao C (2015) The differential role of human macrophage in triggering secondary bystander effects after either gamma-ray or carbon beam irradiation. Cancer Lett 363:92-100

Du S, Zhou L, Alexander GS, Park K, Yang L, Wang N, Zaorsky NG, Ma X, Wang Y, Dicker AP, Lu B (2018) PD-1 Modulates Radiation-Induced Cardiac Toxicity through Cytotoxic T Lymphocytes. J Thorac Oncol 13:510-520

Durante M, Brauer-Krisch E, Hill M (2018) Faster and safer? FLASH ultra-high dose rate in radiotherapy. Br J Radiol 91:20170628

El Kaffas A, Al-Mahrouki A, Hashim A, Law N, Giles A, Czarnota GJ (2018) Role of acid sphingomyelinase and ceramide in mechano-acoustic enhancement of tumor radiation responses. J Natl Cancer Inst. https://doi.org/10.1093/jnci/djy011

Farooque A, Afrin F, Adhikari JS, Dwarakanath BS (2016) Polarization of macrophages towards M1 phenotype by a combination of 2-deoxy-d-glucose and radiation: Implications for tumor therapy. Immunobiology 221:269-281

Favaudon V, Caplier L, Monceau V, Pouzoulet F, Sayarath M, Fouillade C, Poupon MF, Brito I, Hupe P, Bourhis J, Hall J, Fontaine JJ, Vozenin MC (2014) Ultrahigh dose-rate FLASH irradiation increases the differential response between normal and tumor tissue in mice. Sci Transl Med 6:245ra293

Fernandes-Alnemri T, Yu JW, Datta P, Wu J, Alnemri ES (2009) AIM2 activates the inflammasome and cell death in response to cytoplasmic DNA. Nature 458:509-513

Filatenkov A, Baker J, Mueller AM, Kenkel J, Ahn GO, Dutt S, Zhang N, Kohrt H, Jensen K, Dejbakhsh-Jones S, Shizuru JA, Negrin RN, Engleman EG, Strober S (2015) Ablative tumor radiation can change the tumor immune cell microenvironment to induce durable complete remissions. Clin Cancer Res 21:3727-3739

Finkel P, Frey B, Mayer F, Bösl K, Werthmöller N, Mackensen A, Gaipl US, Ullrich E (2016) The dual role of NK cells in antitumor reactions triggered by ionizing radiation in combination with hyperthermia. OncoImmunology 5:e1101206

Frey B, Rubner Y, Kulzer L, Werthmoller N, Weiss EM, Fietkau R, Gaipl US (2014) Antitumor immune responses induced by ionizing irradiation and further immune stimulation. Cancer Immunol Immunother 63:29-36

Fu J, Yuan D, Xiao L, Tu W, Dong C, Liu W, Shao C (2016) The crosstalk between alpha-irradiated Beas-2B cells and its bystander U937 cells through MAPK and NF-kappaB signaling pathways. Mutat Res 783:1-8
Fujino G, Noguchi T, Takeda K, Ichijo H (2006) Thioredoxin and protein kinases in redox signaling. Semin Cancer Biol 16:427-435

Gaber MW, Sabek OM, Fukatsu K, Wilcox HG, Kiani MF, Merchant TE (2003) Differences in ICAM-1 and TNF-alpha expression between large single fraction and fractionated irradiation in mouse brain. Int J Radiat Biol 79:359-366

Gamrekelashvili J, Greten TF, Korangy F (2015) Immunogenicity of necrotic cell death. Cell Mol Life Sci 72:273-283

Gao L, Li FS, Chen XH, Liu QW, Feng JB, Liu QJ, Su X (2014) Radiation induces phosphorylation of STAT3 in a doseand time-dependent manner. Asian Pac J Cancer Prev 15:6161-6164

Garnett CT, Palena C, Chakraborty M, Tsang KY, Schlom J, Hodge JW (2004) Sublethal irradiation of human tumor cells modulates phenotype resulting in enhanced killing by cytotoxic T lymphocytes. Can Res 64:7985-7994

Golden EB, Chhabra A, Chachoua A, Adams S, Donach M, FentonKerimian M, Friedman K, Ponzo F, Babb JS, Goldberg J, Demaria S, Formenti SC (2015) Local radiotherapy and granulocytemacrophage colony-stimulating factor to generate abscopal responses in patients with metastatic solid tumours: a proof-ofprinciple trial. Lancet Oncol 16:795-803

Goldin-Lang P, Niebergall F, Antoniak S, Szotowski B, Rosenthal P, Pels K, Schultheiss HP, Rauch U (2007) Ionizing radiation induces upregulation of cellular procoagulability and tissue factor expression in human peripheral blood mononuclear cells. Thromb Res 120:857-864

Grass GD, Krishna N, Kim S (2016) The immune mechanisms of abscopal effect in radiation therapy. Curr Probl Cancer 40:10-24

Gutin PH, Iwamoto FM, Beal K, Mohile NA, Karimi S, Hou BL, Lymberis S, Yamada Y, Chang J, Abrey LE (2009) Safety and efficacy of bevacizumab with hypofractionated stereotactic irradiation for recurrent malignant gliomas. Int J Radiat Oncol Biol Phys 75:156-163

Hagelstrom RT, Askin KF, Williams AJ, Ramaiah L, Desaintes C, Goodwin EH, Ullrich RL, Bailey SM (2008) DNA-PKcs and ATM influence generation of ionizing radiation-induced bystander signals. Oncogene 27:6761-6769

Haimovitz-Friedman A, Kan CC, Ehleiter D, Persaud RS, McLoughlin M, Fuks Z, Kolesnick RN (1994) Ionizing radiation acts on cellular membranes to generate ceramide and initiate apoptosis. J Exp Med 180:525-535

Han SK, Song JY, Yun YS, Yi SY (2006) Effect of gamma radiation on cytokine expression and cytokine-receptor mediated STAT activation. Int J Radiat Biol 82:686-697

Hanahan D, Weinberg RA (2011) Hallmarks of cancer: the next generation. Cell 144:646-674

Handschel J, Prott FJ, Sunderkotter C, Metze D, Meyer U, Joos U (1999) Irradiation induces increase of adhesion molecules and accumulation of beta2-integrin-expressing cells in humans. Int J Radiat Oncol Biol Phys 45:475-481

Haston CK, Tomko TG, Godin N, Kerckhoff L, Hallett MT (2005) Murine candidate bleomycin induced pulmonary fibrosis susceptibility genes identified by gene expression and sequence analysis of linkage regions. J Med Genet 42:464-473

He M, Zhao M, Shen B, Prise KM, Shao C (2011) Radiationinduced intercellular signaling mediated by cytochrome-c via a p53-dependent pathway in hepatoma cells. Oncogene 30:1947-1955

He M, Ye S, Ren R, Dong C, Xie Y, Yuan D, Shao C (2012) Cytochrome-c mediated a bystander response dependent on inducible nitric oxide synthase in irradiated hepatoma cells. $\mathrm{Br}$ J Cancer 106:889

He M, Dong C, Xie Y, Li J, Yuan D, Bai Y, Shao C (2014) Reciprocal bystander effect between alpha-irradiated macrophage and 
hepatocyte is mediated by cAMP through a membrane signaling pathway. Mutat Res 763-764:1-9

Hinrichs CS, Watroba NL, Rezaishiraz H, Giese W, Hurd T, Fassl KA, Edge SB (2004) Lymphedema secondary to postmastectomy radiation: incidence and risk factors. Ann Surg Oncol 11:573-580

Hong JH, Chiang CS, Campbell IL, Sun JR, Withers HR, McBride WH (1995) Induction of acute phase gene expression by brain irradiation. Int J Radiat Oncol Biol Phys 33:619-626

Hong JH, Chiang CS, Tsao CY, Lin PY, McBride WH, Wu CJ (1999) Rapid induction of cytokine gene expression in the lung after single and fractionated doses of radiation. Int $\mathrm{J}$ Radiat Biol 75:1421-1427

Hu B, Jin C, Li H-B, Tong J, Ouyang X, Cetinbas NM, Zhu S, Strowig T, Lam FC, Zhao C, Henao-Mejia J, Yilmaz O, Fitzgerald KA, Eisenbarth SC, Elinav E, Flavell RA (2016) The DNA-sensing AIM2 inflammasome controls radiation-induced cell death and tissue injury. Science 354:765

Hu ZI, McArthur HL, Ho AY (2017) The abscopal effect of radiation therapy: what is it and how can we use it in breast cancer? Curr Breast Cancer Rep 9:45-51

Hwang SY, Jung JS, Kim TH, Lim SJ, Oh ES, Kim JY, Ji KA, Joe EH, Cho KH, Han IO (2006) Ionizing radiation induces astrocyte gliosis through microglia activation. Neurobiol Dis 21:457-467

Iliakis G, Okayasu R (1988) The level of induced DNA double-strand breaks does not correlate with cell killing in X-irradiated mitotic and G1-phase CHO cells. Int J Radiat Biol 53:395-404

Inoue H, Tani K (2014) Multimodal immunogenic cancer cell death as a consequence of anticancer cytotoxic treatments. Cell Death Differen 21:39-49

Irigoyen M, Anso E, Martinez E, Garayoa M, Martinez-Irujo JJ, Rouzaut A (2007) Hypoxia alters the adhesive properties of lymphatic endothelial cells. A transcriptional and functional study. Biochem Biophys Acta 1773:880-890

Ivanov VN, Hei TK (2014a) Radiation-induced glioblastoma signaling cascade regulates viability, apoptosis and differentiation of neural stem cells (NSC). Apoptosis 19:1736-1754

Ivanov VN, Hei TK (2014b) A role for TRAIL/TRAIL-R2 in radiationinduced apoptosis and radiation-induced bystander response of human neural stem cells. Apoptosis 19:399-413

Jaffray DA (2012) Image-guided radiotherapy: from current concept to future perspectives. Nat Rev Clin Oncol 9:688-699

Jin X, Liang B, Chen Z, Liu X, Zhang Z (2014) The dynamic changes of capillary permeability and upregulation of VEGF in rats following radiation-induced brain injury. Microcirculation 21:171-177

Jo GH, Bogler O, Chwae YJ, Yoo H, Lee SH, Park JB, Kim YJ, Kim JH, Gwak HS (2015) Radiation-induced autophagy contributes to cell death and induces apoptosis partly in malignant glioma cells. Cancer Res Treat 47:221-241

Julow J, Szeifert GT, Balint K, Nyary I, Nemes Z (2007) The role of microglia/macrophage system in the tissue response to I-125 interstitial brachytherapy of cerebral gliomas. Neurol Res 29:233-238

Kachikwu EL, Iwamoto KS, Liao Y-P, DeMarco JJ, Agazaryan N, Economou JS, McBride WH, Schaue D (2011) Radiation enhances regulatory $\mathrm{T}$ cell representation. Int $\mathrm{J}$ Radiat Oncol Biol Phys 81:1128-1135

Kamrava M, Bernstein MB, Camphausen K, Hodge JW (2009) Combining radiation, immunotherapy, and antiangiogenesis agents in the management of cancer: the Three Musketeers or just another quixotic combination? Mol Biosyst 5:1262-1270

Kang MA, So EY, Simons AL, Spitz DR, Ouchi T (2012) DNA damage induces reactive oxygen species generation through the H2AXNox1/Rac1 pathway. Cell Death Dis 3:e249
Kim SH, Lim DJ, Chung YG, Cho TH, Lim SJ, Kim WJ, Suh JK (2002) Expression of TNF-alpha and TGF-beta 1 in the rat brain after a single high-dose irradiation. J Korean Med Sci 17:242-248

Kim EJ, Lee YJ, Kang S, Lim YB (2014) Ionizing radiation activates PERK/eIF2alpha/ATF4 signaling via ER stress-independent pathway in human vascular endothelial cells. Int J Radiat Biol 90:306-312

Kioi M, Vogel H, Schultz G, Hoffman RM, Harsh GR, Brown JM (2010) Inhibition of vasculogenesis, but not angiogenesis, prevents the recurrence of glioblastoma after irradiation in mice. J Clin Investig 120:694-705

Klug F, Prakash H, Huber PE, Seibel T, Bender N, Halama N, Pfirschke C, Voss RH, Timke C, Umansky L, Klapproth K, Schakel K, Garbi N, Jager D, Weitz J, Schmitz-Winnenthal H, Hammerling GJ, Beckhove P (2013) Low-dose irradiation programs macrophage differentiation to an iNOS(+)/M1 phenotype that orchestrates effective $\mathrm{T}$ cell immunotherapy. Cancer Cell 24:589-602

Kozin SV, Kamoun WS, Huang Y, Dawson MR, Jain RK, Duda DG (2010) Recruitment of myeloid but not endothelial precursor cells facilitates tumor regrowth after local irradiation. Can Res 70:5679-5685

Krigsfeld GS, Kennedy AR (2013) Is disseminated intravascular coagulation the major cause of mortality from radiation at relatively low whole body doses? Radiat Res 180:231-234

Krigsfeld GS, Sanzari JK, Kennedy AR (2012) The effects of proton radiation on the prothrombin and partial thromboplastin times of irradiated ferrets. Int J Radiat Biol 88:327-334

Krigsfeld GS, Savage AR, Sanzari JK, Wroe AJ, Gridley DS, Kennedy AR (2013) Mechanism of hypocoagulability in proton-irradiated ferrets. Int J Radiat Biol 89:823-831

Krysko DV, Garg AD, Kaczmarek A, Krysko O, Agostinis P, Vandenabeele P (2012) Immunogenic cell death and DAMPs in cancer therapy. Nat Rev Cancer 12:860-875

Kunala S, Macklis RM (2001) Ionizing radiation induces CD20 surface expression on human B cells. Int J Cancer 96:178-181

Lai A, Filka E, McGibbon B, Nghiemphu PL, Graham C, Yong WH, Mischel P, Liau LM, Bergsneider M, Pope W, Selch M, Cloughesy T (2008) Phase II pilot study of bevacizumab in combination with temozolomide and regional radiation therapy for up-front treatment of patients with newly diagnosed glioblastoma multiforme: interim analysis of safety and tolerability. Int J Radiat Oncol Biol Phys 71:1372-1380

Lamkanfi M, Dixit VM (2014) Mechanisms and functions of inflammasomes. Cell 157:1013-1022

Lan J, Li R, Yin L-M, Deng L, Gui J, Chen B-Q, Zhou L, Men M-B, Huang Q-R, Mo X-M, Wei Y-Q, Lu B, Dicker A, Xue J-X, Lu Y (2018) Targeting MDSCs and PD-L1 confers the therapeutic advantage of ablative hypofractionated radiotherapy over conventional fractionated radiotherapy. Int J Radiat Oncol Biol Phys 101:74-87

Lauber K, Ernst A, Orth M, Herrmann M, Belka C (2012) Dying cell clearance and its impact on the outcome of tumor radiotherapy. Front Oncol 2:116

Lee Y, Auh SL, Wang Y, Burnette B, Wang Y, Meng Y, Beckett M, Sharma R, Chin R, Tu T, Weichselbaum RR, Fu Y-X (2009) Therapeutic effects of ablative radiation on local tumor require CD8(+) T cells: changing strategies for cancer treatment. Blood 114:589-595

Lee WH, Sonntag WE, Mitschelen M, Yan H, Lee YW (2010) Irradiation induces regionally specific alterations in pro-inflammatory environments in rat brain. Int J Radiat Biol 86:132-144

Levine B, Klionsky DJ (2004) Development by self-digestion: molecular mechanisms and biological functions of autophagy. Dev Cell $6: 463-477$ 
Li W, Wang G, Cui J, Xue L, Cai L (2004) Low-dose radiation (LDR) induces hematopoietic hormesis: LDR-induced mobilization of hematopoietic progenitor cells into peripheral blood circulation. Exp Hematol 32:1088-1096

Li J, Wang YAN, Du L, Xu C, Cao JIA, Wang QIN, Liu Q, Fan F (2014) Radiation-induced cytochrome c release and the neuroprotective effects of the pan-caspase inhibitor z-VAD-fmk in the hypoglossal nucleus. Exp Ther Med 7:383-388

Linke SP, Clarkin KC, Wahl GM (1997) p53 mediates permanent arrest over multiple cell cycles in response to gamma-irradiation. Can Res 57:1171-1179

Liu Y-g, Chen J-k, Zhang Z-t, Ma X-j, Chen Y-c, Du X-m, Liu H, Zong Y, Lu G-c (2017) NLRP3 inflammasome activation mediates radiation-induced pyroptosis in bone marrow-derived macrophages. Cell Death Dis 8:e2579

Lobrich M, Ikpeme S, Kiefer J (1994a) DNA double-strand break measurement in mammalian cells by pulsed-field gel electrophoresis: an approach using restriction enzymes and gene probing. Int J Radiat Biol 65:623-630

Lobrich M, Ikpeme S, Kiefer J (1994b) Measurement of DNA doublestrand breaks in mammalian cells by pulsed-field gel electrophoresis: a new approach using rarely cutting restriction enzymes. Radiat Res 138:186-192

Lorimore SA, Coates PJ, Scobie GE, Milne G, Wright EG (2001) Inflammatory-type responses after exposure to ionizing radiation in vivo: a mechanism for radiation-induced bystander effects? Oncogene 20:7085-7095

Lotze MT, Zeh HJ, Rubartelli A, Sparvero LJ, Amoscato AA, Washburn NR, Devera ME, Liang X, Tor M, Billiar T (2007) The grateful dead: damage-associated molecular pattern molecules and reduction/oxidation regulate immunity. Immunol Rev 220:60-81

Lupu-Plesu M, Claren A, Martial S, N'Diaye PD, Lebrigand K, Pons N, Ambrosetti D, Peyrottes I, Feuillade J, Herault J, Dufies M, Doyen J, Pages G (2017) Effects of proton versus photon irradiation on (lymph)angiogenic, inflammatory, proliferative and anti-tumor immune responses in head and neck squamous cell carcinoma. Oncogenesis 6:e354

Mackonis EC, Suchowerska N, Zhang M, Ebert M, McKenzie DR, Jackson M (2007) Cellular response to modulated radiation fields. Phys Med Biol 52:5469-5482

Mandapathil M, Szczepanski MJ, Szajnik M, Ren J, Lenzner DE, Jackson EK, Gorelik E, Lang S, Johnson JT, Whiteside TL (2009) Increased ectonucleotidase expression and activity in regulatory $\mathrm{T}$ cells of patients with head and neck cancer. Clin Cancer Res 15:6348-6357

Marathe S, Schissel SL, Yellin MJ, Beatini N, Mintzer R, Williams KJ, Tabas I (1998) Human vascular endothelial cells are a rich and regulatable source of secretory sphingomyelinase. Implications for early atherogenesis and ceramide-mediated cell signaling. $\mathrm{J}$ Biol Chem 273:4081-4088

Marconi R, Strolin S, Bossi G, Strigari L (2017) A meta-analysis of the abscopal effect in preclinical models: Is the biologically effective dose a relevant physical trigger? PLoS ONE 12:e0171559

Mazo IB, Quackenbush EJ, Lowe JB, von Andrian UH (2002) Total body irradiation causes profound changes in endothelial traffic molecules for hematopoietic progenitor cell recruitment to bone marrow. Blood 99:4182-4191

McArt DG, McKerr G, Saetzler K, Howard CV, Downes CS, Wasson GR (2010) Comet sensitivity in assessing DNA damage and repair in different cell cycle stages. Mutagenesis 25:299-303

McDonald JT, Kim K, Norris A, Vlashi E, Phillips TM, Lagadec C, Donna LD, Ratikan J, Szelag H, Hlatky L, McBride WH (2010) Ionizing radiation activates the Nrf2 antioxidant response. Can Res 70:8886-8895
McKay MJ, Taubman KL, Foroudi F, Lee ST, Scott AM (2018) Molecular imaging using PET/CT for radiotherapy planning of adult cancers: current status and expanding applications. Int J Radiat Oncol Biol Phys, https://doi.org/10.1016/j.ijrobp.2018.03.013

Mencin A, Kluwe J, Schwabe RF (2009) Toll-like receptors as targets in chronic liver diseases. Gut 58:704-720

Meng A, Wang Y, Van Zant G, Zhou D (2003) Ionizing radiation and busulfan induce premature senescence in murine bone marrow hematopoietic cells. Can Res 63:5414-5419

Miller YI, Choi SH, Wiesner P, Fang L, Harkewicz R, Hartvigsen K, Boullier A, Gonen A, Diehl CJ, Que X, Montano E, Shaw PX, Tsimikas S, Binder CJ, Witztum JL (2011) Oxidation-specific epitopes are danger-associated molecular patterns recognized by pattern recognition receptors of innate immunity. Circ Res 108:235-248

Miralbell R, Roberts SA, Zubizarreta E, Hendry JH (2012) Dosefractionation sensitivity of prostate cancer deduced from radiotherapy outcomes of 5,969 Patients in seven international institutional datasets: $\alpha / \beta=1.4(0.9-2.2)$ Gy. Int J Radiat Oncol Biol Phys 82:e17-e24

Miszczyk J, Rawojć K, Panek A, Borkowska A, Prasanna PGS, Ahmed MM, Swakoń J, Gałaś A (2018) Do protons and X-rays induce cell-killing in human peripheral blood lymphocytes by different mechanisms? Clin Transl Radiat Oncol 9:23-29

Mitteer R, Wang Y, Shah J, Gordon S, Fager M, Butter P-P, Jun Kim H, Guardiola-Salmeron C, Carabe-Fernandez A, Fan Y (2015) Proton beam radiation induces DNA damage and cell apoptosis in glioma stem cells through reactive oxygen species. Sci Rep 5:13961

Mole RH (1953) Whole body irradiation; radiobiology or medicine? Br J Radiol 26:234-241

Montay-Gruel P, Petersson K, Jaccard M, Boivin G, Germond J-F, Petit B, Doenlen R, Favaudon V, Bochud F, Bailat C, Bourhis J, Vozenin M-C (2017) Irradiation in a flash: Unique sparing of memory in mice after whole brain irradiation with dose rates above 100 Gy/s. Radiother Oncol 124:365-369

Moore AH, Olschowka JA, Williams JP, Paige SL, O'Banion MK (2004) Radiation-induced edema is dependent on cyclooxygenase 2 activity in mouse brain. Radiat Res 161:153-160

Moravan MJ, Olschowka JA, Williams JP, O'Banion MK (2011) Cranial irradiation leads to acute and persistent neuroinflammation with delayed increases in T-cell infiltration and CD11c expression in C57BL/6 mouse brain. Radiat Res 176:459-473

Moretti L, Cha YI, Niermann KJ, Lu B (2007) Switch between apoptosis and autophagy: radiation-induced endoplasmic reticulum stress? Cell Cycle 6:793-798

Movahedi K, Guilliams M, Van den Bossche J, Van den Bergh R, Gysemans C, Beschin A, De Baetselier P, Van Ginderachter JA (2008) Identification of discrete tumor-induced myeloid-derived suppressor cell subpopulations with distinct T cell-suppressive activity. Blood 111:4233-4244

Nagasawa H, Little JB (1992) Induction of sister chromatid exchanges by extremely low doses of alpha-particles. Can Res 52:6394-6396

Narayanan PK, Goodwin EH, Lehnert BE (1997) Alpha particles initiate biological production of superoxide anions and hydrogen peroxide in human cells. Can Res 57:3963-3971

Narayanan PK, LaRue KE, Goodwin EH, Lehnert BE (1999) Alpha particles induce the production of interleukin- 8 by human cells. Radiat Res 152:57-63

$\mathrm{Ng}$ J, Dai T (2016) Radiation therapy and the abscopal effect: a concept comes of age. Ann Transl Med 4:118

Ngwa W, Irabor OC, Schoenfeld JD, Hesser J, Demaria S, Formenti SC (2018) Using immunotherapy to boost the abscopal effect. Nat Rev Cancer 18:313-322 
Nutting CM, Morden JP, Harrington KJ, Urbano TG, Bhide SA, Clark C, Miles EA, Miah AB, Newbold K, Tanay M, Adab F, Jefferies SJ, Scrase C, Yap BK, A'Hern RP, Sydenham MA, Emson M, Hall E, on behalf of the Ptmg (2011) Parotid-sparing intensity modulated versus conventional radiotherapy in head and neck cancer (PARSPORT): a phase 3 multicentre randomised controlled trial. Lancet Oncol 12:127-136

Ogawa Y, Nishioka A, Hamada N, Terashima M, Inomata T, Yoshida S, Seguchi H, Kishimoto S (1997) Expression of fas (CD95/ APO-1) antigen induced by radiation therapy for diffuse B-cell lymphoma: immunohistochemical study. Clin Cancer Res 3:2211-2216

Ohshima Y, Tsukimoto M, Takenouchi T, Harada H, Suzuki A, Sato M, Kitani H, Kojima S (2010) Gamma-irradiation induces P2 × (7) receptor-dependent ATP release from B16 melanoma cells. Biochem Biophys Acta 1800:40-46

Olive PL (1999) DNA damage and repair in individual cells: applications of the comet assay in radiobiology. Int J Radiat Biol 75:395-405

Paris F, Fuks Z, Kang A, Capodieci P, Juan G, Ehleiter D, HaimovitzFriedman A, Cordon-Cardo C, Kolesnick R (2001) Endothelial apoptosis as the primary lesion initiating intestinal radiation damage in mice. Science 293:293

Park SS, Dong H, Liu X, Harrington SM, Krco CJ, Grams MP, Mansfield AS, Furutani KM, Olivier KR, Kwon ED (2015) PD-1 restrains radiotherapy-induced abscopal effect. Cancer Immunol Res 3:610-619

Paun A, Kunwar A, Haston CK (2015) Acute adaptive immune response correlates with late radiation-induced pulmonary fibrosis in mice. Radiat Oncol 10:45

Pena LA, Fuks Z, Kolesnick RN (2000) Radiation-induced apoptosis of endothelial cells in the murine central nervous system: protection by fibroblast growth factor and sphingomyelinase deficiency. Can Res 60:321-327

Peslak SA, Wenger J, Bemis JC, Kingsley PD, Koniski AD, McGrath KE, Palis J (2012) EPO-mediated expansion of late-stage erythroid progenitors in the bone marrow initiates recovery from sublethal radiation stress. Blood 120:2501-2511

Petrek JA, Senie RT, Peters M, Rosen PP (2001) Lymphedema in a cohort of breast carcinoma survivors 20 years after diagnosis. Cancer 92:1368-1377

Qu X, Yu J, Bhagat G, Furuya N, Hibshoosh H, Troxel A, Rosen J, Eskelinen E-L, Mizushima N, Ohsumi Y, Cattoretti G, Levine B (2003) Promotion of tumorigenesis by heterozygous disruption of the beclin 1 autophagy gene. J Clin Investig 112:1809-1820

Qu Y, Jin S, Zhang A, Zhang B, Shi X, Wang J, Zhao Y (2010) Gamma-ray resistance of regulatory CD4 + CD25 + Foxp3 + T cells in mice. Radiat Res 173:148-157

Rainaldi G, Ferrante A, Indovina PL, Santini MT (2003) Induction of apoptosis or necrosis by ionizing radiation is dose-dependent in MG-63 osteosarcoma multicellular spheroids. Anticancer Res 23:2505-2518

Raju U, Gumin GJ, Tofilon PJ (2000) Radiation-induced transcription factor activation in the rat cerebral cortex. Int J Radiat Biol 76:1045-1053

Rastogi S, Boylan M, Wright EG, Coates PJ (2012a) Interactions of apoptotic cells with macrophages in radiation-induced bystander signaling. Radiat Res 179:135-145

Rastogi S, Coates PJ, Lorimore SA, Wright EG (2012b) Bystander-type effects mediated by long-lived inflammatory signaling in irradiated bone marrow. Radiat Res 177:244-250

Rastogi S, Boylan M, Wright EG, Coates PJ (2013) Interactions of apoptotic cells with macrophages in radiation-induced bystander signaling. Radiat Res 179:135-145
Reynders K, Illidge T, Siva S, Chang JY, De Ruysscher D (2015) The abscopal effect of local radiotherapy: using immunotherapy to make a rare event clinically relevant. Cancer Treat Rev 41:503-510

Rezacova M, Rudolfova G, Tichy A, Bacikova A, Mutna D, Havelek R, Vavrova J, Odrazka K, Lukasova E, Kozubek S (2011) Accumulation of DNA damage and cell death after fractionated irradiation. Radiat Res 175:708-718

Rho HS, Kim SH, Lee CE (2005) Mechanism of NF-kappaB activation induced by gamma-irradiation in B lymphoma cells: role of Ras. J Toxicol Environ Health A 68:2019-2031

Robins HI, Won M, Seiferheld WF, Schultz CJ, Choucair AK, Brachman DG, Demas WF, Mehta MP (2006) Phase 2 trial of radiation plus high-dose tamoxifen for glioblastoma multiforme: RTOG protocol BR-0021. Neuro-Oncology 8:47-52

Rosin DL, Okusa MD (2011) Dangers within: DAMP responses to damage and cell death in kidney disease. J Am Soc Nephrol $22: 416-425$

Ross GM (1999) Induction of cell death by radiotherapy. Endocr Relat Cancer 6:41-44

Ross CC, MacLeod SL, Plaxco JR, Froude JW, Fink LM, Wang J, Stites WE, Hauer-Jensen M (2008) Inactivation of thrombomodulin by ionizing radiation in a cell-free system: possible implications for radiation responses in vascular endothelium. Radiat Res 169:408-416

Rube CE, Fricke A, Wendorf J, Stutzel A, Kuhne M, Ong MF, Lipp P, Rube C (2010) Accumulation of DNA double-strand breaks in normal tissues after fractionated irradiation. Int J Radiat Oncol Biol Phys 76:1206-1213

Rubinsztein DC, Gestwicki JE, Murphy LO, Klionsky DJ (2007) Potential therapeutic applications of autophagy. Nat Rev Drug Discov 6:304-312

Rudqvist NP, Pilones KA, Lhuillier C, Wennerberg E, Sidhom JW, Emerson RO, Robins HS, Schneck J, Formenti SC, Demaria S (2018) Radiotherapy and CTLA-4 Blockade Shape the TCR Repertoire of Tumor-Infiltrating T Cells. Cancer Immunol Res 6:139-150

Santin AD, Rose GS, Hiserodt JC, Fruehauf J, Eck LM, Garcia RI, Schranz V, Disaia PJ, Pecorelli S, Granger GA (1996) Effects of cytokines combined with high-dose gamma irradiation on the expression of major histocompatibility complex molecules and intercellular adhesion molecule-1 in human ovarian cancers. Int J Cancer 65:688-694

Schaue D, McBride WH (2010) Links between innate immunity and normal tissue radiobiology. Radiat Res 173:406-417

Schaue D, Comin-Anduix B, Ribas A, Zhang L, Goodglick L, Sayre JW, Debucquoy A, Haustermans K, McBride WH (2008) T-cell responses to survivin in cancer patients undergoing radiation therapy. Clin Cancer Res 14:4883-4890

Schaue D, Kachikwu EL, McBride WH (2012a) Cytokines in radiobiological responses: a review. Radiat Res 178:505-523

Schaue D, Ratikan JA, Iwamoto KS, McBride WH (2012b) Maximizing tumor immunity with fractionated radiation. Int J Radiat Oncol Biol Phys 83:1306-1310

Shakibaei M, Schulze-Tanzil G, Takada Y, Aggarwal BB (2005) Redox regulation of apoptosis by members of the TNF superfamily. Antioxid Redox Signal 7:482-496

Shao C, Stewart V, Folkard M, Michael BD, Prise KM (2003) Nitric oxide-mediated signaling in the bystander response of individually targeted glioma cells. Can Res 63:8437-8442

Shao C, Lyng FM, Folkard M, Prise KM (2006) Calcium fluxes modulate the radiation-induced bystander responses in targeted glioma and fibroblast cells. Radiat Res 166:479-487 
Shao C, Folkard M, Prise KM (2007) Role of TGF- $\beta 1$ and nitric oxide in the bystander response of irradiated glioma cells. Oncogene 27:434

Shao C, Prise KM, Folkard M (2008) Signaling factors for irradiated glioma cells induced bystander responses in fibroblasts. Mutat Res 638:139-145

Shareef MM, Cui N, Burikhanov R, Gupta S, Satishkumar S, Shajahan S, Mohiuddin M, Rangnekar VM, Ahmed MM (2007) Role of tumor necrosis factor-alpha and TRAIL in high-dose radiationinduced bystander signaling in lung adenocarcinoma. Can Res 67:11811-11820

Sheard MA, Vojtesek B, Janakova L, Kovarik J, Zaloudik J (1997) Up-regulation of Fas (CD95) in human p53wild-type cancer cells treated with ionizing radiation. Int J Cancer 73:757-762

Sica A, Allavena P, Mantovani A (2008) Cancer related inflammation: the macrophage connection. Cancer Lett 267:204-215

Siva S, MacManus MP, Martin RF, Martin OA (2015) Abscopal effects of radiation therapy: A clinical review for the radiobiologist. Cancer Lett 356:82-90

Solito S, Pinton L, Damuzzo V, Mandruzzato S (2012) Highlights on molecular mechanisms of MDSC-mediated immune suppression: paving the way for new working hypotheses. Immunol Invest 41:722-737

Sridharan V, Schoenfeld JD (2015) Immune effects of targeted radiation therapy for cancer. Discov Med 19:219-228

Stafford JH, Hirai T, Deng L, Chernikova SB, Urata K, West BL, Brown JM (2016) Colony stimulating factor 1 receptor inhibition delays recurrence of glioblastoma after radiation by altering myeloid cell recruitment and polarization. Neuro-oncolology 18:797-806

Stoecklein VM, Osuka A, Ishikawa S, Lederer MR, Wanke-Jellinek L, Lederer JA (2015) Radiation exposure induces inflammasome pathway activation in immune cells. J Immunol 194:1178-1189

Stupp R, Mason WP, van den Bent MJ, Weller M, Fisher B, Taphoorn MJ, Belanger K, Brandes AA, Marosi C, Bogdahn U, Curschmann J, Janzer RC, Ludwin SK, Gorlia T, Allgeier A, Lacombe D, Cairncross JG, Eisenhauer E, Mirimanoff RO (2005) Radiotherapy plus concomitant and adjuvant temozolomide for glioblastoma. N Engl J Med 352:987-996

Stuschke M, Thames HD (1997) Hyperfractionated radiotherapy of human tumors: overview of the randomized clinical trials. Int J Radiat Oncol Biol Phys 37:259-267

Suzuki K, Mori I, Nakayama Y, Miyakoda M, Kodama S, Watanabe M (2001) Radiation-induced senescence-like growth arrest requires TP53 function but not telomere shortening. Radiat Res 155:248-253

Szumiel I (1998) Monitoring and signaling of radiation-induced damage in mammalian cells. Radiat Res 150:S92-S101

Tan SM, Kapp M, Flechsig C, Kapp K, Rachor JE, Eyrich M, Loeffler J, Einsele H, Grigoleit GU (2013) Stimulating surface molecules, Th1-polarizing cytokines, proven trafficking - a new protocol for the generation of clinical-grade dendritic cells. Cytotherapy 15:492-506

Tateishi Y, Sasabe E, Ueta E, Yamamoto T (2008) Ionizing irradiation induces apoptotic damage of salivary gland acinar cells via NADPH oxidase 1-dependent superoxide generation. Biochem Biophys Res Commun 366:301-307

Todd DG, Mikkelsen RB (1994) Ionizing radiation induces a transient increase in cytosolic free [Ca2+] in human epithelial tumor cells. Can Res 54:5224-5230

Toivonen P, Kivela T (2012) Infiltrating macrophages in extratumoural tissues after brachytherapy of uveal melanoma. Acta Ophthalmol 90:341-349

Tomura M, Honda T, Tanizaki H, Otsuka A, Egawa G, Tokura Y, Waldmann H, Hori S, Cyster JG, Watanabe T, Miyachi Y, Kanagawa O, Kabashima K (2010) Activated regulatory T cells are the major $\mathrm{T}$ cell type emigrating from the skin during a cutaneous immune response in mice. J Clin Investig 120:883-893

Trainor C, Butterworth KT, McGarry CK, McMahon SJ, O'Sullivan JM, Hounsell AR, Prise KM (2012) DNA damage responses following exposure to modulated radiation fields. PLoS ONE 7:e43326

Tsai CS, Chen FH, Wang CC, Huang HL, Jung SM, Wu CJ, Lee CC, McBride WH, Chiang CS, Hong JH (2007) Macrophages from irradiated tumors express higher levels of iNOS, arginase-I and COX-2, and promote tumor growth. International Journal of Radiation Oncology Biology Physics 68:499-507

Tsukimoto M, Tamaishi N, Homma T, Kojima S (2010) Low-dose gamma-ray irradiation induces translocation of $\mathrm{Nrf} 2$ into nuclear in mouse macrophage RAW264.7 cells. J Radiat Res $51: 349-353$

Uchimura E, Watanabe N, Niwa O, Muto M, Kobayashi Y (2000) Transient infiltration of neutrophils into the thymus in association with apoptosis induced by whole-body X-irradiation. J Leukoc Biol 67:780-784

Van der Meeren A, Vandamme M, Squiban C, Gaugler MH, Mouthon MA (2003) Inflammatory reaction and changes in expression of coagulation proteins on lung endothelial cells after total-body irradiation in mice. Radiat Res 160:637-646

Vanpouille-Box C, Alard A, Aryankalayil MJ, Sarfraz Y, Diamond JM, Schneider RJ, Inghirami G, Coleman CN, Formenti SC, Demaria S (2017) DNA exonuclease Trex1 regulates radiotherapy-induced tumour immunogenicity. Nat Commun 8:15618

Vicari AP, Treilleux I, Lebecque S (2004) Regulation of the trafficking of tumour-infiltrating dendritic cells by chemokines. Semin Cancer Biol 14:161-169

Wagner V, Andrlikova J, Palek V, Wagnerova M (1978) The levels of immunoglobulins (IgG. IgA. IgM) under the effect of age and exposure to the mining environment in uranium industry. Strahlentherapie 154:406-412

Wang J, Zheng H, Ou X, Fink LM, Hauer-Jensen M (2002) Deficiency of microvascular thrombomodulin and up-regulation of proteaseactivated receptor- 1 in irradiated rat intestine: possible link between endothelial dysfunction and chronic radiation fibrosis. Am J Pathol 160:2063-2072

Wang Y, Boerma M, Zhou D (2016) Ionizing radiation-induced endothelial cell senescence and cardiovascular diseases. Radiat Res 186:153-161

Watters D (1999) Molecular mechanisms of ionizing radiation-induced apoptosis. Immunol Cell Biol 77:263

Wennerberg E, Kawashima N, Demaria S (2015) Adenosine regulates radiation therapy-induced anti-tumor immunity. J Immunother Cancer 3:P378-P378

Whelan TJ, Pignol JP, Levine MN, Julian JA, MacKenzie R, Parpia S, Shelley W, Grimard L, Bowen J, Lukka H, Perera F, Fyles A, Schneider K, Gulavita S, Freeman C (2010) Long-term results of hypofractionated radiation therapy for breast cancer. $\mathrm{N}$ Engl J Med 362:513-520

Xie Y, Ye S, Zhang J, He M, Dong C, Tu W, Liu P, Shao C (2016) Protective effect of mild endoplasmic reticulum stress on radiationinduced bystander effects in hepatocyte cells. Sci Rep 6:38832

Xu J, Escamilla J, Mok S, David J, Priceman S, West B, Bollag G, McBride W, Wu L (2013) CSF1R signaling blockade stanches tumor-infiltrating myeloid cells and improves the efficacy of radiotherapy in prostate cancer. Can Res 73:2782-2794

Yang R, Cai Z, Zhang Y, Yutzy WH, Roby KF, Roden RB (2006) CD80 in immune suppression by mouse ovarian carcinoma-associated Gr-1 + CD11b + myeloid cells. Can Res 66:6807-6815

Yao Z, Jones J, Kohrt H, Strober S (2011) Selective resistance of CD44hi T cells to p53-dependent cell death results in persistence of immunologic memory after total body irradiation. J Immunol 187:4100-4108 
Yue Z, Jin S, Yang C, Levine AJ, Heintz N (2003) Beclin 1, an autophagy gene essential for early embryonic development, is a haploinsufficient tumor suppressor. Proc Natl Acad Sci USA 100:15077-15082

Zhang X, Niedermann G (2018) Abscopal effects with hypofractionated schedules extending into the effector phase of the tumorspecific T-cell response. Int J Radiat Oncol Biol Phys https://doi. org/10.1016/j.ijrobp.2018.01.094

Zhang L, Yuan H, Burk LM, Inscoe CR, Hadsell MJ, Chtcheprov P, Lee YZ, Lu J, Chang S, Zhou O (2014) Image-guided microbeam irradiation to brain tumour bearing mice using a carbon nanotube X-ray source array. Phys Med Biol 59:1283-1303

Zheng X, Guo Y, Wang L, Zhang H, Wang S, Wang L, An L, Zhou X, Li X, Yao C (2015) Recovery profiles of T-cell subsets following low-dose total body irradiation and improvement with cinnamon. Int J Radiat Oncol Biol Phys 93:1118-1126

Zheng X, Jin X, Li F, Liu X, Liu Y, Ye F, Li P, Zhao T, Li Q (2017) Inhibiting autophagy with chloroquine enhances the anti-tumor effect of high-LET carbon ions via ER stress-related apoptosis. Med Oncol 34:25

Zhou H, Ivanov VN, Gillespie J, Geard CR, Amundson SA, Brenner DJ, Yu Z, Lieberman HB, Hei TK (2005) Mechanism of radiation-induced bystander effect: role of the cyclooxygenase-2 signaling pathway. Proc Natl Acad Sci USA 102:14641-14646

Zhou H, Ivanov VN, Lien YC, Davidson M, Hei TK (2008) Mitochondrial function and nuclear factor-kappaB-mediated signaling in radiation-induced bystander effects. Can Res 68:2233-2240 